\title{
Characterisation of road-dust sediment in urban systems: a review of a global challenge
}

\author{
Haydn M. Haynes ${ }^{1} \cdot$ Kevin G. Taylor ${ }^{1} \cdot$ James Rothwell ${ }^{2} \cdot$ Patrick Byrne $^{3}$
}

Received: 14 April 2020 / Accepted: 8 October 2020 / Published online: 21 October 2020

(C) The Author(s) 2020

\begin{abstract}
Purpose The proportion of people living in urbanised areas is predicted to rise to $>65 \%$ by 2050 , and therefore, more humans than ever will be exposed to urban environmental pollution. Accumulation of organic and inorganic substances on street and road surfaces is a major global challenge requiring scientifically robust methods of establishing risk that inform management strategies. This aim of this contribution is to critically review the global literature on urban road-deposited sediment contamination with a specific focus on variability in sampling and analytical methods.

Materials and methods In order to assess the concentration of contaminants in global road-deposited sediment (RDS), a comprehensive search of published RDS studies was completed. We review methodological approaches used in RDS studies to highlight the variability in datasets as a result of sampling technique, grain size fractionation, geochemical and mineralogical characterisation methods and establishing the influence of local geology on contaminant concentrations. We also consider emerging contaminants in RDS, and we provide a workflow diagram which promotes a standardised sampling and analysis regime that we believe can reduce data variability and promote collaboration when it comes to tackling the important issue of RDS contamination.

Results and discussion Across the literature, Asia (except China) and Africa are underrepresented in RDS studies despite these continents having the largest and fastest growing populations, respectively. The removal of tetraethyl lead from gasoline produced a noticeable decrease in lead concentrations in global RDS, and platinum group element (PGE) concentrations in RDS were consistent with catalytic converter usage. Research into the impact of electric vehicles on non-exhaust emissions suggests other contaminants such as zinc may become more prominent in the future. Most RDS studies consider grain size fractions larger than $>20 \mu \mathrm{m}$ due to sampling constraints despite RDS $<20 \mu \mathrm{m}$ being most relevant to human health. The use of chemical extraction methods to establish contaminant geochemistry is popular; however, most extraction procedures are not relevant or specific to minerals identified in RDS through microscopic and spectroscopic investigations.

Conclusions This review highlights considerable variability in sampling and analytical approach which makes it difficult to identify broad global patterns in RDS contamination. To remove this variability from future RDS research, this review suggests a workflow plan which attempts to improve the comparability between RDS studies. Such comparability is crucial in identifying more discrete RDS trends and informing future emission policy.
\end{abstract}

Keywords Contaminants $\cdot$ Road-deposited sediment $\cdot$ Urban areas

Responsible editor: Sophie Ayrault

Kevin G. Taylor

kevin.taylor@manchester.ac.uk

1 Department of Earth and Environmental Sciences, The University of Manchester, Oxford Road, Manchester M13 9PL, UK

2 Department of Geography, The University of Manchester, Oxford Road, Manchester M13 9PL, UK

3 School of Biological and Environmental Sciences, Liverpool John Moores University, L3 3AF, Liverpool, UK

\section{Introduction}

The global population as of 2019 was approximately 7.71 billion (UN 2019b). This figure is expected to rise to 9.74 billion by 2050 (UN 2019b). The proportion of people living in urban areas has increased rapidly from $29.6 \%$ in 1950 to $55.3 \%$ in 2018, with the value projected to reach $68 \%$ by 2050 (UN 2019a). As the population of urban areas increases, the number of people exposed to urban contaminants increases, along with the amount of particulates being produced (Liang 
and Yang 2019). Therefore, understanding contaminant loadings in urban environments, and the physical, chemical and biological transport pathways, is a major global challenge.

Road-deposited sediments (RDS) are an accumulation of particulate matter on street surfaces and are abundant in all urban environments (Taylor and Owens 2009). RDS is a composite of natural sediments, including soil material, leaf litter as well as atmospheric particles, and anthropogenic sediments, produced by the deterioration of vehicle components, and combustion products (Beckwith et al. 1986), construction material, road salt, road paint and pedestrian debris. RDS can contain a variety of contaminants including fine particulates (Alves et al. 2018) and toxic metals (Zafra et al. 2011).

Contaminants in RDS are prone to remobilisation to the local atmosphere (Alves et al. 2018) or can be transported in stormwater runoff to other ecologically sensitive locations (Goonetilleke et al. 2017). The monitoring of RDS contaminants has been conducted by public bodies (USEPA 1973) and research institutions (Day et al. 1975) since the 1970s with key findings leading to the clean-up of urban environments (Stojiljkovic et al. 2019). However, with a technologically advancing society, contaminant contributions to RDS continue to change. The emergence of electric and hybrid vehicles will reduce exhaust emissions, but it has the potential to increase the concentration of non-exhaust emissions (Timmers and Achten 2016). As the demand for fossil fuel vehicles continues to increase, the use of platinum group elements (PGEs) will also rise (Zhang et al. 2016b), with a potential shift to less valuable base metals depending on future developments (Alikin et al. 2013). Emerging contaminants may also continue to be identified in RDS. These include anthropogenic magnetite which has been identified in human brain tissue (Maher et al. 2016), polycyclic aromatic hydrocarbons (PAHs) which are considered to be carcinogenic (Suman et al. 2016), and microplastics (Kole et al. 2017).

There is a wealth of information on contaminants in RDS. Several reviews of toxic metals (Wei and Yang 2010) and PGEs have been published (Hwang et al. 2016), but none of these have sufficiently described RDS contamination on a global scale. Understanding RDS on a global scale is crucial for hazard identification and prioritisation, to make future predictions about the impacts of urbanisation on human health, and the environment. Aside from developing an understanding of the nature and scale of global road dust contamination, it is also important to develop a better understanding of the key variables that influence RDS concentrations and loadings. Locality-linked variables will help us to tackle the challenge of RDS in an increasingly urbanised world, whilst experimental variables can help us to find the best available techniques.

This review is structured into five parts: (1) we describe the methodological approach to the review; (2) we provide an update on our current understanding of global RDS contamination, drawing on a range of case studies; (3) we critically review methodological approaches used in RDS studies to highlight the variability in datasets as a result of sampling technique, grain size fractionation and chemical extraction; (4) we describe the statistical techniques used to compare RDS contamination to the local geology; (5) we discuss the techniques for describing the morphology of RDS, and their mineralogical composition; (6) we consider emerging contaminants in RDS; and (7) we provide a workflow diagram which promotes a standardised sampling regime that we believe can reduce data variability and promote collaboration when it comes to tackling the important issue of RDS.

\section{Review methodology}

Central to meeting the objectives of this review, targeted searches for RDS surveys were carried out by inputting "road dust", or "road deposited sediment", and key words (PGEs, toxic metals, etc.,) into Web of Science (Clarivate Analytics, Philadelphia, PA, USA) and identifying publications that had produced RDS data. Cited references and citing publications were also identified in order to increase the scope of data acquisition. RDS studies were deemed suitable for this review if they were published by a peer-reviewed journal (Adamiec et al. 2016) or by a governmental body (USEPA 1973). RDS contaminant concentrations published in reviews were also accepted if the cited publication was locatable and complied with the constraints listed above. Once a list of sources had been produced, a series of Microsoft Excel (Office 365, Microsoft, Redmond, WA, USA) spreadsheets were used to separate references by their content (toxic metals, PGEs, etc.). The spreadsheets were used to collect a detailed set of criteria including the concentrations of key contaminants $(\mathrm{Pb}, \mathrm{Zn}, \mathrm{Cu}$, etc.), publication year, units (ppm, $\mathrm{mg} \mathrm{kg}^{-1}$, etc.), grain size fractions studied, country, city/location, location descriptions (inner city, major roads, etc.), extraction method, sampling method, analytical method and any noteworthy additional information. Publications that discussed RDS data but did not provide numerical values were excluded from the analysis but were used in the context of discussion, where appropriate.

Having assembled the spreadsheets, some modifications were made to simplify further the analysis and improve the relation to urbanised RDS. These were converting units to ppm so unit discrepancies did not have to be assessed when looking at sub-datasets, and the removal of data that indicated they were not from an urban area, or may have been influenced by a point source such as industrial effluents (Brunekreef et al. 1981). Table 1 gives a breakdown of the location descriptors excluded, and the reasoning behind them.

Where studies reported means and associated individualised data, only the individualised datum was included to avoid replication. Data were not included where there was any 
Table 1 Description of the sublocations excluded from further analysis whilst assessing urban RDS contamination

\begin{tabular}{ll}
\hline Description & Reasoning \\
\hline $\begin{array}{l}\text { Background } \\
\text { Car parks }\end{array}$ & $\begin{array}{l}\text { Used to compare natural concentrations to RDS } \\
\text { Area might be sheltered from climatic conditions and may not be subject } \\
\text { to road sweeping regimes } \\
\text { Control }\end{array}$ \\
Used to compare natural concentrations to RDS \\
Lead stations & Pollution point source \\
Parks & Pollution point source \\
Playgrounds & Sampling not taking place on a road surface \\
Rural & Sampling not taking place on a road surface \\
Scrap yard & Not relevant to the urban environment \\
Squares & Pollution point source \\
\hline
\end{tabular}

uncertainty about the form of the site (i.e. whether urban or not) - a point discussed under the workflow diagram section.

An important area of urban contamination that has been omitted from this review is that of air particulates and human health. It is now widely understood that urban air particulates have numerous human health impacts and air pollutants such as $\mathrm{PM}_{2.5}$ (particulate matter less than $2.5 \mu \mathrm{m}$ ) have been linked to respiratory illnesses (Xing et al. 2016), and reductions in life expectancies (Bennett et al. 2019). There exists a vast and rapidly developing body of literature on this subject with major publications in the medical and atmospheric science literature. RDS and airborne particulates are, of course, interlinked. Indeed, some studies (see examples cited in Thorpe and Harrison 2008) estimate that more than 50\% of airborne particulate matter may be due to resuspension of RDS. However, given the vastness of the literature on airborne particulates, and the frequent focus of investigations on human physiology, consideration of the airborne particulate literature is considered beyond the scope of this review. Readers who are interested in the subject of airborne particulates are directed to the excellent reviews by Gulia et al. (2015) and Xie et al. (2017).

\section{Global populations in urban centres}

In order to assess the concentration of contaminants in global RDS, a comprehensive search of RDS surveys was completed. To ensure the relevance of this review to global RDS, attempts were made to encompass RDS studies from as many localities as possible. Table 2 shows the number of studies conducted in each country.

Asia was the most studied continent accounting for 67 of the RDS studies in this review with 38 studies in China alone (Table 2). Europe was the next most represented continent with 47 studies (Table 2), with most of the studies from the
UK (25) and Spain (6). The last continent with high representation was North America (24) (Table 2), with 15 studies from the USA and six from Canada. In relation to global urbanisation, $53.7 \%$ of the world's urban population lives in Asia, with Africa, Europe and South America, each making up approximately $13.0 \%$ (UN 2019a). Despite a plethora of studies conducted in China, there is a lack of research into RDS contamination in major urban centres elsewhere on the Asian continent. RDS studies in Africa are scarce. This is a concern as Africa is expected to see an accelerated growth in urbanisation in the future (UN 2019a). There are currently 20 countries/ overseas territories/administrative regions that are considered to have urbanisation percentages greater than $90.0 \%$ (UN 2019a). Of these, only China, Singapore, United States Virgin Islands, Argentina, Japan, Netherlands and Jordan are considered in this review. By 2050, the list of urbanised countries/overseas territories/administrative regions with percentages greater than $90.0 \%$ is expected to expand to 42 areas (UN 2019a). In addition to the previously described $90 \%$ urbanised areas, this review considers Sweden, Bahrain, Brazil, New Zealand, Australia, Norway and the UK. It is clear from this analysis that the overall proportion of heavily urbanised centres considered is low, and that more studies from a variety of urbanised areas are required. Only three RDS studies from Africa in the last 5 years were recorded in this review (Mafuyai et al. 2015; Benhaddya et al. 2016; Maina et al. 2018), highlighting the need for a focus on cities in Africa.

\section{Global road dust composition}

One of the aims of this study is to assess the composition of RDS in urban areas. Some of the key components of RDS are toxic metals which are deposited as a result of fuel combustion, road surface wear and vehicular wear (Zafra et al. 2011). 
Table 2 The number of RDS studies conducted in each country considered in this review

\begin{tabular}{|c|c|}
\hline Country & Studies \\
\hline Algeria & 1 \\
\hline Angola & 1 \\
\hline Argentina & 1 \\
\hline Australia & 3 \\
\hline Austria & 1 \\
\hline Bahrain & 1 \\
\hline Bangladesh & 1 \\
\hline Brazil & 3 \\
\hline Canada & 6 \\
\hline China & 38 \\
\hline Colombia & 1 \\
\hline Ecuador & 1 \\
\hline Egypt & 2 \\
\hline Fiji & 1 \\
\hline France & 1 \\
\hline Germany & 1 \\
\hline Ghana & 2 \\
\hline Greece & 3 \\
\hline Hungary & 1 \\
\hline India & 5 \\
\hline Italy & 1 \\
\hline Jamaica & 1 \\
\hline Japan & 2 \\
\hline Jordan & 3 \\
\hline Kenya & 1 \\
\hline Malaysia & 2 \\
\hline Mexico & 1 \\
\hline Nepal & 1 \\
\hline Netherlands & 1 \\
\hline New Zealand & 3 \\
\hline Nigeria & 1 \\
\hline Norway & 1 \\
\hline Pakistan & 1 \\
\hline Poland & 1 \\
\hline Portugal & 1 \\
\hline Saudi Arabia & 1 \\
\hline Scotland & 1 \\
\hline Singapore & 2 \\
\hline South Korea & 6 \\
\hline Spain & 6 \\
\hline Sweden & 2 \\
\hline Switzerland & 1 \\
\hline Taiwan & 1 \\
\hline Thailand & 1 \\
\hline Turkey & 2 \\
\hline UK & 25 \\
\hline USA & 15 \\
\hline United States Virgin Islands & 1 \\
\hline Venezuela & 1 \\
\hline
\end{tabular}

The main contributors to toxic metal contamination in this review are lead and zinc which have an average of $651 \mathrm{ppm}$ and 760 ppm, respectively (Fig. 1). Other key metal components include copper (236 ppm), chromium (118 ppm) and nickel (49 ppm), with lower concentrations of cobalt (14 ppm) and cadmium (5 ppm) (Fig. 1). Arsenic (14 ppm) and mercury (600 ppb) were identified in a limited number of locations (Fig. 1) but were not widely analysed. A large amount of variability exists in the global dataset. For example, in the case of lead, the mean value (651 ppm) is close to the third quartile (761 ppm), whilst the median (226 ppm) is close to the lower quartile (83 ppm) (Fig. 1). The maximum lead concentration was $10,700 \mathrm{ppm}$, with the minimum being 2 ppm (Fig. 1). The reasons for this variability in the dataset become more apparent when the change over time is considered (see below).

The pre-1990 mean lead concentration in RDS was 1750 ppm, with a decrease to 785 ppm between 1990 and 1999 and to 231 ppm from the year 2000 onwards (Fig. 2). The third quartile for 1990-1999 is 840 ppm compared to 261 ppm from 2000 onwards. However, the first quartile values are similar $(\sim 72.0 \mathrm{ppm})$. These data are reflective of global trends in the use of leaded petrol. The toxicity of lead has been recognised for centuries due to its neurotoxicity, and the clear behavioural changes associated with long-term lead exposure (Goyer 1993). Despite these health concerns, lead was used in a variety of domestic products including paint (Inskip and Hutton 1987). Lead was also used as a gasoline additive in the form of tetraethyl lead. Studies showed that lead from leaded gasoline was accumulating in RDS (Duggan and Williams 1977), and that such pollution was also linked to increased lead concentrations in the blood of children (Gallacher et al. 1984). Unleaded gasoline was introduced to some markets such as the USA as early as 1974 (Sperling and Dill 1988). However, according to the observed trend, lead levels in RDS did not begin to significantly decline until the 1990s (Fig. 2). This is because many markets continued to use leaded petrol, with concentrations of lead in gasoline being gradually reduced up until its eventual ban across most of the globe by 2000 (Xu et al. 2012). Whilst largely eliminated from global fuels, tetraethyl lead still has limited use in some aviation fuels $\left(A v_{\text {gas }}\right)$ (Miranda et al. 2011), as well as in gasoline in a few countries such as Iraq (Hamad et al. 2015). Lead is still used in lead-acid car batteries (Zhang et al. 2016a), and the wearing of car parts and road surfaces (Zafra et al. 2011) will be a contributory factor towards present-day lead emissions. Compared to pre-1990 RDS concentrations, the lead levels in post-2000 RDS are below domestic soil limits set out by the USEPA, which specify maximum concentrations of 400 ppm for children's play areas and 1200 ppm for bare soil (USEPA 2019).

The decline of lead concentrations in global RDS is a key example of the benefit that environmental policy can have on reducing urban environmental pollution and its associated 
Fig. 1 Box and whisker plot depicting the concentrations (ppm) of key RDS metals ( $\mathrm{Pb}, \mathrm{Zn}$, $\mathrm{Cu}, \mathrm{Co}, \mathrm{Cr}, \mathrm{Cd}, \mathrm{Ni}, \mathrm{As}, \mathrm{Hg}$ ) obtained from past RDS surveys. Statistical information is also provided

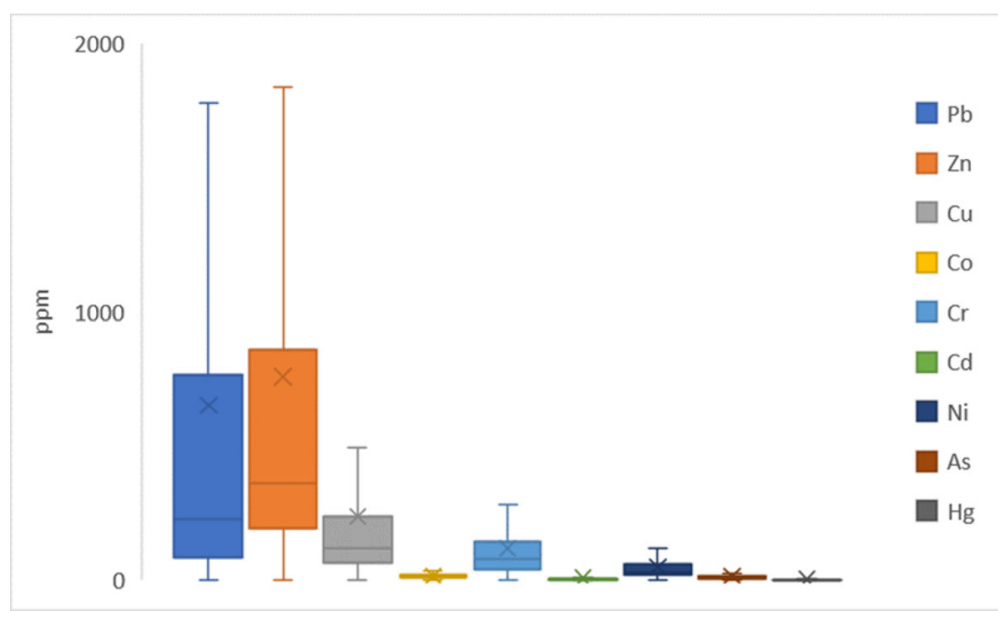

\begin{tabular}{llllllllll}
\hline & $\mathrm{Pb}$ & $\mathrm{Zn}$ & $\mathrm{Cu}$ & $\mathrm{Co}$ & $\mathrm{Cr}$ & $\mathrm{Cd}$ & $\mathrm{Ni}$ & $\mathrm{As}$ & $\mathrm{Hg}$ \\
\hline Mean & 651 & 760 & 236 & 13.8 & 118 & 4.90 & 49.4 & 14.4 & 0.624 \\
Median & 226 & 360 & 116 & 10.3 & 77.8 & 1.40 & 30.2 & 8.80 & 0.510 \\
1st Quartile & 762 & 850 & 234 & 18.0 & 140 & 3.62 & 58.7 & 12.2 & 0.825 \\
3rd Quartile & 82.5 & 195 & 60.9 & 7.23 & 40.0 & 0.565 & 19.3 & 4.94 & 0.305 \\
Minimum & 2.00 & 0.130 & 0.0500 & 2.67 & 1.13 & 0.0200 & 0.00 & 0.500 & 0.0200 \\
Maximum & 10700 & 10100 & 9070 & 51 & 1490 & 200 & 1450 & 181 & 2.56 \\
\hline
\end{tabular}

negative impacts. The concentration of lead in children's blood has decreased, providing societal and economic benefits (Gilbert and Weiss 2006). Without the presence of tetraethyl lead in petrol, the prominence of toxic metals in RDS has shifted towards non-exhaust emission sources (Simons 2016). Non-exhaust emissions are derived from numerous sources including, but not limited to, tyre wear, engine wear, brake components, oils, bodywork corrosion and urban construction materials (road surfaces, buildings, etc.) (Zafra et al. 2011). This represents a major challenge for identification of individual sources and apportionment of metal loadings. However, chemical extractions, sequential extractions and imaging techniques (Fujiwara et al. 2011) offer the opportunity to assist in the identification of sources.

Global mean zinc concentrations in RDS declined from $1430 \mathrm{ppm}$ before 1990 to $478 \mathrm{ppm}$ in the 1990s but have since seen a modest increase to $629 \mathrm{ppm}$ from the year 2000 and onwards (Fig. 3). Zinc is a key component of car tyres accounting for approximately $1 \%$ of the total weight (Milani et al. 2004). Zinc is also found in various automotive oils, brake pads and road construction materials (Zafra et al. 2011). The decline of zinc concentrations could plausibly be linked to the clean-up of industrial sites (Nicholson et al. 2003) and the implementation of street sweeping (German and Svensson 2002). The sale of cars globally has increased from 29 million in 1980 to 65 million in 2014, with this value expected to double by 2050 (Hao et al. 2016). As vehicle usage has increased, the deposition of tyre tread on road surfaces has likely also increased, leading to increases in the deposition of zinc contaminants. Another important factor when it comes to tyre wear and zinc deposition is vehicle weight (Simons 2016).
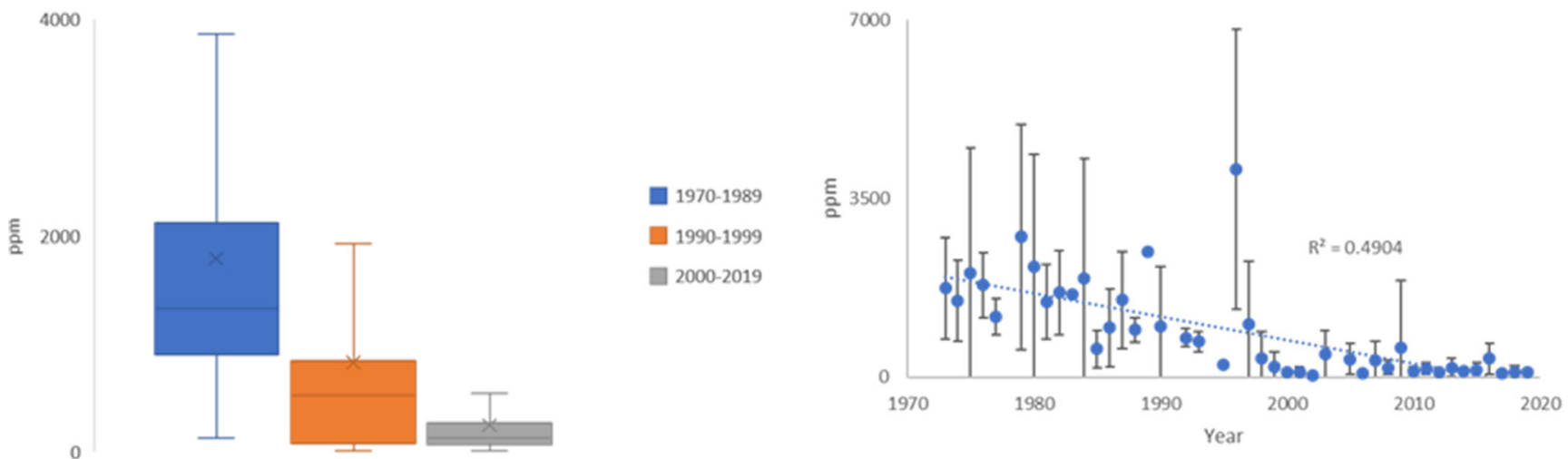

Fig. 2 A box and whisker plot, and a scatter graph depicting the changes in RDS lead concentrations over time (years) 
Fig. 3 Changes in RDS concentrations of zinc portrayed in a box and whisker chart

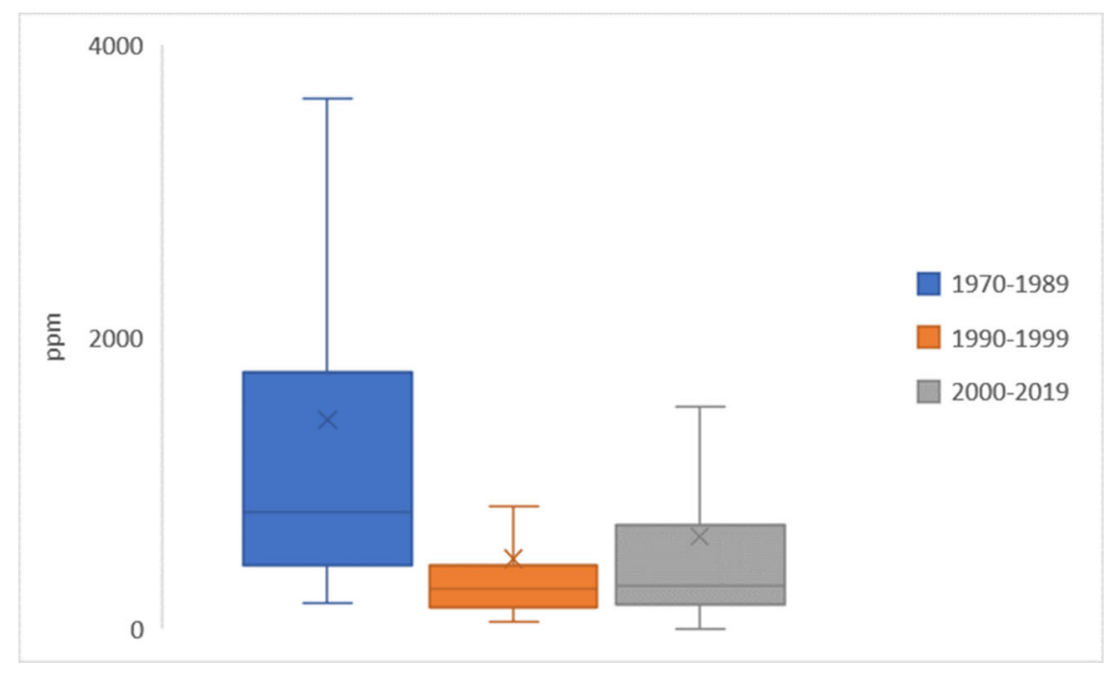

The weight of vehicles is a key consideration when it comes to understanding the future composition of RDS. As the automotive industry shifts towards electric and hybrid vehicles, the incorporation of batteries into cars is increasing vehicle weight (Timmers and Achten 2016). Heavier cars produce larger amounts of non-exhaust emissions due to increased brake, tyre and road wear (Simons 2016). All the toxic metals considered in this study (except arsenic and mercury) have been implicated in these non-exhaust emission sources, but no significant shifts in the temporal data of RDS concentrations have been observed. Whilst the implications of electric vehicle weight may increase non-exhaust RDS emissions, several benefits of increased electric vehicle use include zero exhaust emissions, reduced brake wear when regenerative braking technologies are implemented (Wager et al. 2018) and a significant reduction in lubricating oils. A lack of clear temporal trends is a challenge when trying to discern the future trend of toxic metal RDS loadings in urbanised centres. A considerable amount of variability exists in the dataset due to a wide variety of location-specific and survey-specific factors. In order to address future trends more effectively, attempts were made to understand some of the variables present. Location-specific trends are addressed in the next section by focusing on the data obtained from mainland China and Hong Kong. These areas have been the attention of a large number of studies (Table 3), and Hong Kong is one of the most urbanised regions in the world (UN 2019a).

\section{China}

The first RDS study in China in this review was conducted in 1979 (Ho 1979). Since then, the population of China has increased from 1 billion (1980) to 1.43 billion (2019), with the population expected to remain stable until 2050 (UN 2019b). Over the same period, the percentage of people living in urban environments in China has increased from 19.4 to $61.4 \%$ (2020), with $78.3 \%$ of the population predicted to live in urban environments by 2050 (UN 2019a). Table 3 shows the RDS studies conducted in China over this time and their publication year.

The number of studies from Beijing and Hong Kong represents almost half of the studies conducted across China. Most studies in China post-date 2006 but eight studies were conducted in Hong Kong prior to this date (Table 3). Xi' an is the most studied city in recent years (2017 onwards), with recent studies also available for Guiyang, Shijiazhuang and Urumqi cities (Table 3). Figure 4 shows how Hong Kong RDS compares to global values between 1979 and 2008 (the range over which the Hong Kong studies were conducted), and how China RDS (without Hong Kong) compares to global road dusts between 2006 and 2019. This distinction was chosen because Hong Kong is one of the few fully urbanised territories in the world (UN 2019a) and therefore represents a useful case study for RDS in increasingly urbanised areas. The timeframe for the rest of China was chosen to reflect the timespan over which studies in mainland China have been conducted.

Hong Kong RDS contained similar amounts of copper, chromium and cadmium compared to their global counterparts (Fig. 4). However, lead concentrations in Hong Kong RDS (1430 ppm) were higher than the global mean (963 ppm), and the Hong Kong mean zinc concentration (2890 ppm) was almost triple the global value (1050 ppm) (Figs. 1 and 4). It is difficult to establish trends using the lead data as the main source of lead emissions (leaded gasoline) was globally in decline over this period (Fig. 2). Using Hong Kong as an exemplar of significant urbanisation, it is logical to propose that zinc loadings in RDS are highly likely to increase with greater urbanisation. Other modern examples of urbanised centres with high zinc loadings include Buenos Aires (Fujiwara et al. 2011) and Rio de Janeiro (McAlister 
Table 3 Number of times China cities have been surveyed in China in this review

\begin{tabular}{lll}
\hline City & Times surveyed & Years published (number in the same year) \\
\hline Baoji & 2 & 2009,2010 \\
Beijing & 9 & $2007,2008,2010(2), 2012,2013,2015$ (2), 2016 \\
Chengdu & 1 & 2014 \\
Guangzhou & 1 & 2012 \\
Guiyang & 1 & 2017 \\
Hangzhou & 1 & 2009 \\
Hong Kong & 9 & $1979,1982,1983,1987,1990,1998,2001,2003,2008$ \\
Lanzhou & 2 & 2012,2014 \\
Miyun Town & 1 & 2016 \\
Shanghai & 3 & $2008(2), 2013$ \\
Shenyang & 1 & 2008 \\
Shijiazhuang & 1 & 2019 \\
Urumqi City & 1 & 2019 \\
Wuhan & 1 & 2010 \\
Xianyang & 1 & 2013 \\
Xi'an & 5 & $2006,2008,2017,2018,2019$ \\
Zhenjiang & 1 & 2009 \\
Total & 41 & \\
\hline
\end{tabular}

Publication years are also shown, and some studies have surveyed multiple cities et al. 2005). Despite urbanisation in mainland China proceeding at a faster rate than the global average (UN 2019a), the concentration of toxic metals in urban RDS has not reflected this change (Fig. 4). Modern (2006 onwards) RDS in mainland China contained lower mean concentrations of all the studied toxic metals including $82.0 \%$ less cadmium, $54.8 \%$ less copper and $36.2 \%$ less zinc (Fig. 4). The reasons for this trend are unclear. One of the key variables is spatial distribution. China may have the largest number of RDS surveys, but it is also one of the largest countries in the study. Several variables, including grain size and extraction reagents, can also significantly influence RDS contamination results. These variables are discussed below. The China datasets show that in the case of Hong Kong frequent sampling of a heavily urbanised area can give us an understanding of how urbanisation influences RDS. However, a lack of recent sampling means the influence of modern advancements (e.g. electric vehicles) cannot be established. In the case of mainland China, a lack of spatial resolution means an understanding of country-wide urbanisation cannot be established. Overall, the work conducted in China shows us that repeated sampling of heavily urbanised areas can provide us with insights into the impact of urbanisation on the toxic metal loading of RDS. However, country-wide implications of urbanisation cannot be assessed. The establishment of annual RDS surveying programs in globally important urban centres is recommended in order to track modern influences and predict future trends in urban RDS composition.

\section{Compositional analysis methods}

The focus on mainland China and Hong Kong has shown that information can be deduced from regional and country-wide collation of RDS surveys. However, individual studies focus on different grain size fractions, use different chemical reagents and sample their sites in different ways. This increases the variability between datasets, making it difficult to identify trends. The aim of this section is to explore the variables that are present in the methodology of RDS studies. This information can help us to understand the source of some toxic metal emissions and can serve as a structure by which to form a standardised procedure for future RDS surveys. Some of the variation between toxic metal RDS surveys can be attributed to differences in the grain sizes under investigation. Bulk samples do not accurately represent the hazard of RDS, because finer grains are more likely to get resuspended, forming a respirable pollutant (Alves et al. 2018). RDS samples are typically divided into sub-samples in two ways. Some studies divide the bulk sample into sub-samples before the use of single sieves (i.e. $<63 \mu \mathrm{m}$ and $<2000 \mu \mathrm{m}$ ) (Charlesworth and Lees 1999), whilst other studies use stepwise sieving to obtain several grain size ranges (Han et al. 2008). In some experiments, a separate bulk sample is compared to stepwise sorted samples (Zanders 2005). It is common for the Wentworth scale (Wentworth 1922) to be used for size fractionation. However, some single grain size studies use different classifications including the particulate matter (PM) 
Fig. 4 Comparison of Hong Kong and Mainland China toxic metal RDS concentrations with global concentrations over the timeframe in which the studies were published. No nickel data was reported for Hong Kong
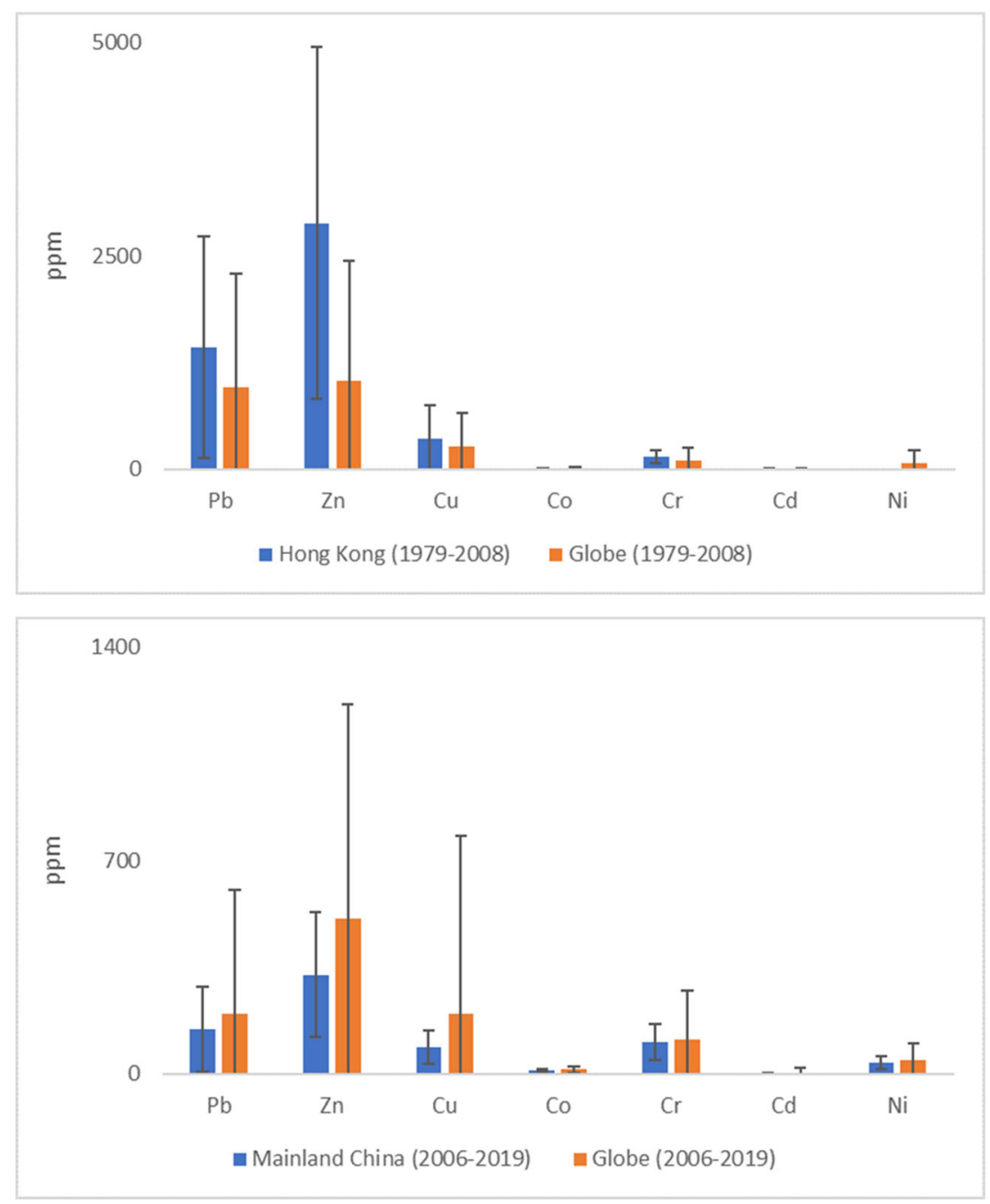

categories (Hetem and Andrade 2016; Alves et al. 2018). The variability in grain size analysis is depicted in Fig. 5. Lanzerstorfer (2018) used a centrifugation technique that produces small grain size ranges $(1-68 \mu \mathrm{m})$ not included in Fig. 5.

It is clear from Fig. 5 that the experimental parameters for multi-grain size papers are inconsistent. However, there does appear to be a limited number of favoured sieve sizes, including $63 \mu \mathrm{m}$ (coarse silt), $125 \mu \mathrm{m}$ (very find sand), $250 \mu \mathrm{m}$ (fine sand) and $500 \mu \mathrm{m}$ (medium sand). Stepwise sieving is preferred in these studies compared to sub-sampling, especially when the age of the studies is considered. Of the studies considered, sub-sampling was used between 1998 and 2002, with stepwise sieving used between 1982 and 2016 (Fig. 5). This is likely due to the additional information that can be discerned when a series of ranges are investigated. In terms of deciding on targeting the most important grain size ranges and producing a standardised methodology, several factors must be considered. Traditional Wentworth-scale sizes can provide us information on how likely the dusts are to be transported during storm events and therefore model the impact on downstream systems (Taylor and Owens 2009). However, in terms of the urban environment and human health, the aerial resuspension, and respiration of these dusts, is likely a greater cause of concern. $\mathrm{PM}_{2.5}(<2.5 \mu \mathrm{m})$ and $\mathrm{PM}_{10}(<10 \mu \mathrm{m})$ are the most widely researched grain sizes when it comes to respiratory illnesses (Harrison and Yin 2000). But, these grain sizes are largely underrepresented in toxic metal RDS studies with only five references out of 152 , considering these fractions in this review. One factor that can be assessed using the data collected in this review is the association of contaminants with different grain sizes.

Figure 6 shows the proportion of toxic metals associated with individual grain size fractions. At grain size fractions larger than $1000 \mu \mathrm{m}$, the toxic metal enrichment is relatively low and is typically below a factor of 2 in toxic metals with the largest datasets (copper, lead, zinc). When the grain size fractions are lower than $1000 \mu \mathrm{m}$, the toxic metal enrichment is higher with the lowest grain size studied being approximately enriched by a factor of 3 or 4 (Fig. 6). In the most extreme 
Fig. 5 Breakdown of the individual grain sizes targeted by authors using multiple grain sizes and the technique employed. Letter a denotes that a bulk sample was also analysed, whilst letter $\mathrm{b}$ shows that a greater than measurement of the largest grain size was conducted

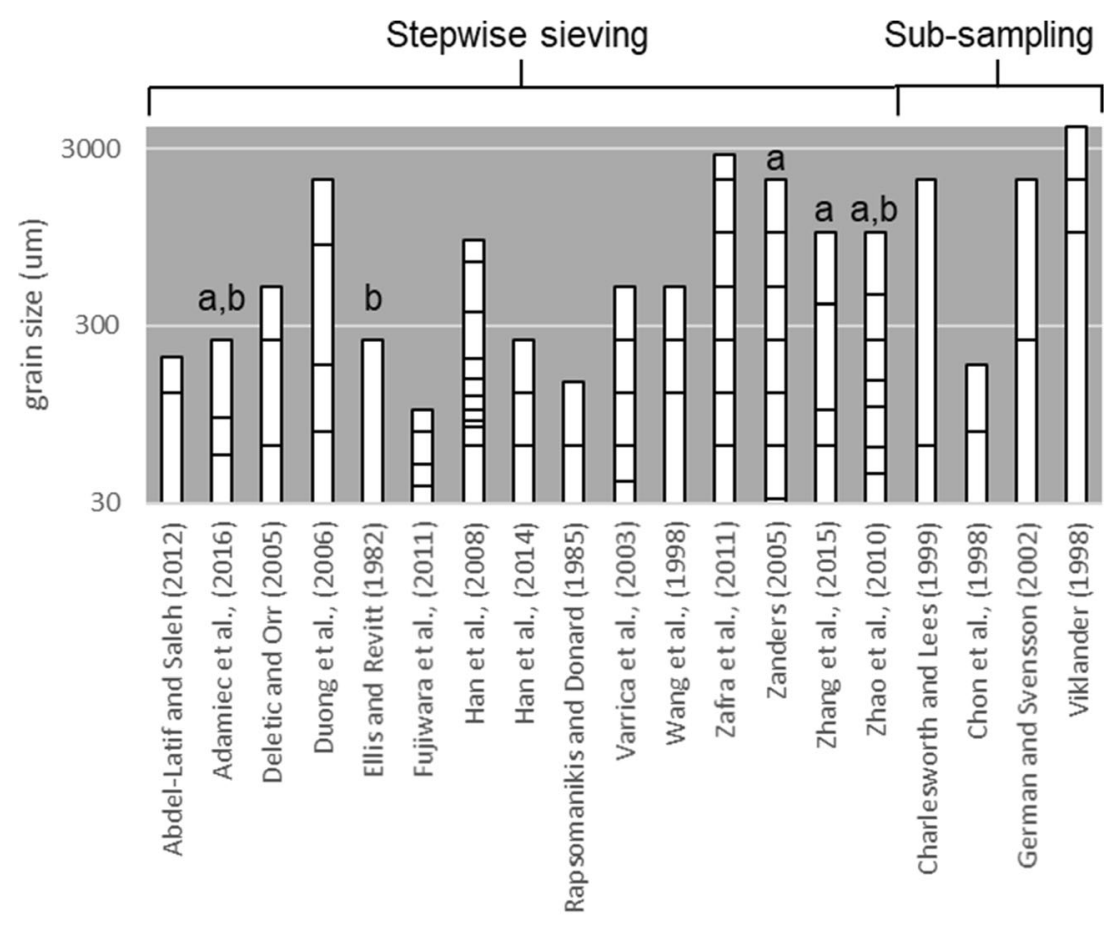

Author examples, the enrichment can be by a factor of 10 or greater (Fig. 6). It is important to consider the grain size distribution of RDS. Despite the larger grain size fractions containing the lowest concentrations of toxic metals, the distribution of grain sizes in RDS is weighted towards the larger grain size fractions (Owens et al. 2011). As a result of this, the bulk loading
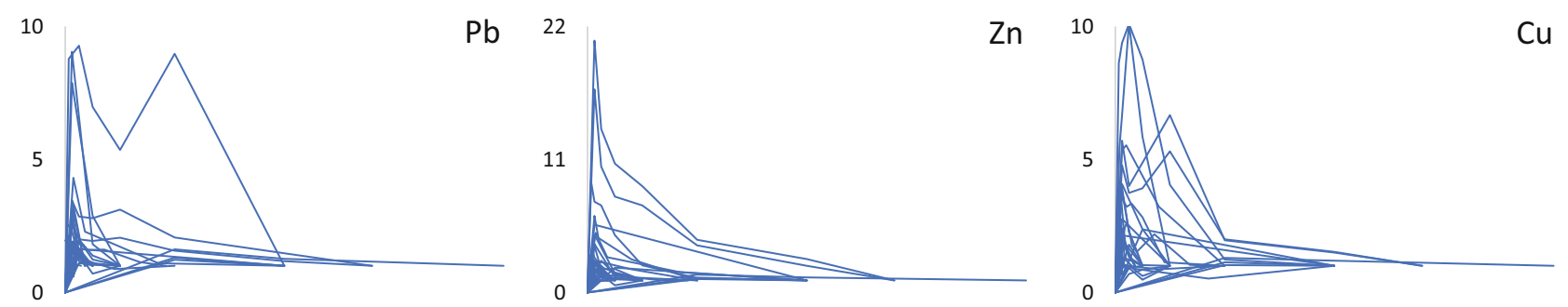

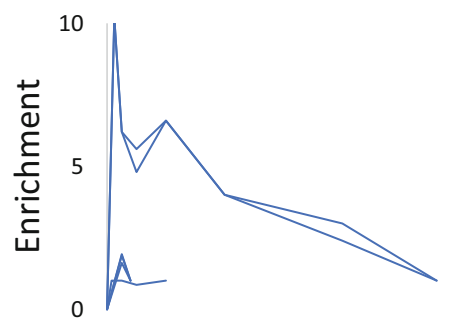

\begin{abstract}
Co
\end{abstract}
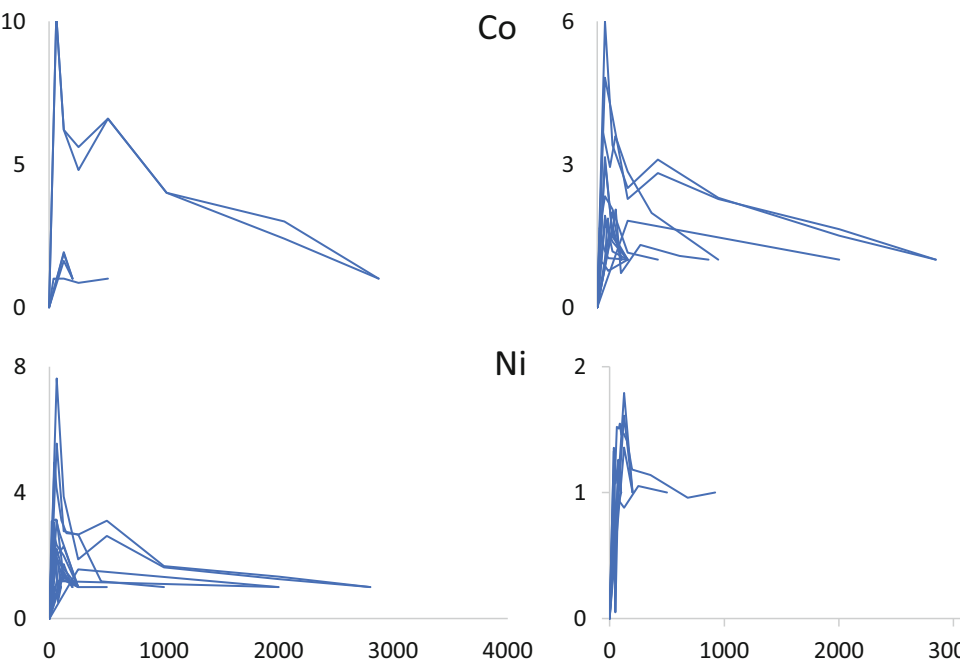

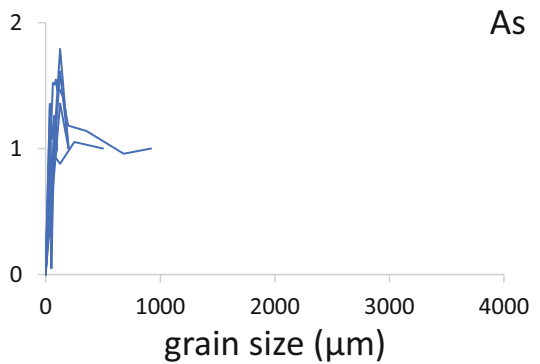

$\mathrm{Cr} 14$
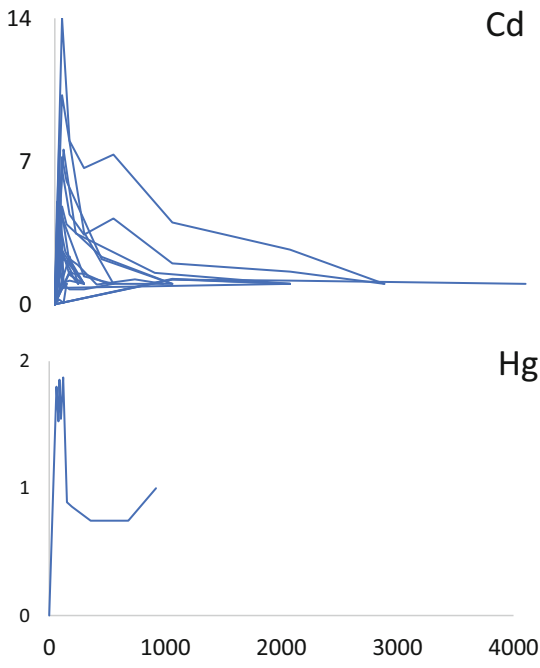

Fig. 6 Enrichment of the concentration of metals $(\mathrm{Pb}, \mathrm{Zn}, \mathrm{Cu}, \mathrm{Co}, \mathrm{Cr}, \mathrm{Cd}, \mathrm{Ni}, \mathrm{As}, \mathrm{Hg})$ by grain size fraction compared to the largest grain size fraction reported 
of toxic metals in RDS is associated with the larger grain size fractions (Stone and Marsalek 1996). This means that studies that focus on grain size fractions below $500 \mu \mathrm{m}$ are not assessing the bulk concentration of toxic metals in RDS. Where studies focus on the small size fractions, the lowest grain size considered in such studies is $20 \mu \mathrm{m}$. This is concerning because it shows that the respirable $2.5 \mu \mathrm{m}$ and $10 \mu \mathrm{m}$ grain sizes likely contain underestimated toxic metal concentrations and are not being captured in global RDS studies. If government agencies are relying on bulk concentrations to assess the risk associated with a toxic metal, the respirable hazard is being underestimated. The reason why most studies do not investigate grain size fractions below $20 \mu \mathrm{m}$ is because it is the lowest achievable grain size fraction by dry sieving (Lanzerstorfer 2018). However, one study used a centrifugation technique in order to examine discrete grain sizes between $1.6 \mu \mathrm{m}$ and $60 \mu \mathrm{m}$ (Lanzerstorfer 2018). Even with these lower grain sizes considered, the highest concentration of toxic metals was still associated with the smallest grain size. More research is required in order to understand the fractionation of toxic metals in RDS by investigating the full spectrum of grain sizes, including those in the respirable size range.

The data in Fig. 6 reveal that different grain size fractions can provide us with information on a variety of factors including bulk toxic metal loadings, transport properties and the hazard associated with the dusts. Several grain size fractions should be considered when it comes to adopting a standardised scheme. The $<1000 \mu \mathrm{m}$ grain size fraction is a good indicator of the bulk concentration of toxic metals associated with RDS, whilst the $<63 \mu \mathrm{m}$ (silt) grain size fraction identifies the portion of the sample which is likely to be transported in storm events (Taylor and Owens 2009). This review also showed that the highest concentration of toxic metal contamination in RDS is associated with the finest fractions (Fig. 6). In terms of human health, the $<2.5 \mu \mathrm{m}$ and $<10 \mu \mathrm{m}$ grain size fractions are respirable and therefore have the potential to pose the greatest harm (Bennett et al. 2019). However, traditional dry sieving techniques cannot separate out grain size less than $20 \mu \mathrm{m}$. In circumstances where dry sieving is being used, we recommend sampling the $<20 \mu \mathrm{m}$ grain size fraction so the closest equivalent to the respirable fractions can be assessed, but $<2.5 \mu \mathrm{m}$ and $<10 \mu \mathrm{m}$ should be analysed where possible.

\section{Chemical extraction methods}

Various reagents are used to solubilise RDS so that the concentration of toxic metals and other contaminants can be determined. Strong acids including nitric and hydrochloric acids are typically used due to their ability to dissolve metals. The ability of these acids to dissolve metals may be improved by altering the experimental conditions (temperature, microwave, etc.), combining strong acids in order to produce chemicals such as aqua regia, or by supplementing them with specific reagents such as the oxidising agents (perchloric acid and hydrogen peroxide). In some cases, the authors may be interested in "biologically-available" toxic metals and choose to use a diluted acid instead (Sutherland 2003). Variation in extraction techniques can yield difficulties when comparing global concentrations of RDS, and therefore, it is important to consider how they influence results. This review categorised studies depending on the reagents they used, but experimental conditions were not considered due to the large variability in temperatures and timings. The studies were also restricted to those completed since the year 2000 in order to avoid the high contaminant loadings associated with historic studies and to place the focus on modern trends in extraction methods. The studies were divided into concentrated acids $50 \%$ of concentrated stock hydrochloric acid, nitric acid, hydrofluoric acid and sulphuric acid or greater), perchloric acid (which includes perchloric acid) and hydrogen peroxide (which includes hydrogen peroxide and diluted acid (weak acids or strong acids diluted below $50 \%$ of concentrated stock)). Although X-ray fluorescence $(\mathrm{XRF})$ does not require a digestion step, it is included here for comparative purposes. Figure 7 shows the number of studies using each method. Strong acids are the most popular choice (37 studies) with the addition of perchloric acid to strong acids in second (26) (Fig. 7). XRF is the next most common choice (19), followed by the addition of hydrogen peroxide (10) and finally diluted acids (3) (Fig. 7).

The concentrations of individual toxic metals were investigated in order to understand how they varied with the reagents used. The data were split into two charts to improve the resolution of the less concentrated metals. Arsenic and mercury were excluded due to the lack of studies reporting them. The data show that with a few exceptions, the proportions of toxic metals identified with each extraction regime are broadly the same (Fig. 8) and mirror the global proportions reported previously (Fig. 8). The XRF and dilute acid procedures produced high concentrations of zinc with mean concentrations of $823 \mathrm{ppm}$ and $436 \mathrm{ppm}$, respectively (Fig. 8). After further inspection of the data, the high zinc concentrations in the dilute acid studies were associated with a single study focused on a less than $50 \mu \mathrm{m}$ grain size fraction in Japan (Wijaya et al. 2012), and in the case of the XRF, studies were associated with a less than $86 \mu \mathrm{m}$ grain size fraction from Hong Kong, China (Yeung et al. 2003); a less than $63 \mu \mathrm{m}$ grain size fraction from Hong Kong (Tanner et al. 2008); and a series of grain size ranges below $250 \mu \mathrm{m}$ from Hamilton, New Zealand (Zanders 2005). This suggests that the small sample sizes, grain size fraction and/or location of the studies may have influenced the results and highlights the complexity of global urban RDS analysis. XRF also produced elevated chromium concentrations (192 ppm), which were also observed when hydrogen peroxide (101 ppm) and perchloric acid (107 ppm) were used (Fig. 8). Concentrated acids and diluted 
Fig. 7 Pie chart showing extraction reagents used for toxic metal RDS studies conducted from the year 2000 and onwards. This chart also includes studies which have used XRF

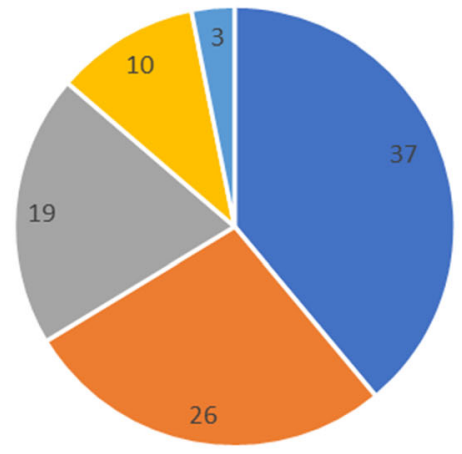

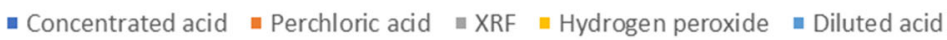

acids produced mean concentrations of chromium of $52.5 \mathrm{ppm}$ and $44.4 \mathrm{ppm}$, respectively (Fig. 8). The addition of hydrogen peroxide and perchloric acid to extraction solutions also produced higher copper concentrations (Fig. 8). Chromium and copper are used in a number of automotive-related alloys to reduce corrosion, especially at elevated temperatures (Talbot and Talbot 2018). Some chromium and copper alloys also show resistance to strong acids (Bellezze et al. 2018), and
Fig. 8 Variation in toxic metal concentrations of urban RDS observed when different extraction reagents are used (concentrated acid, diluted acid, addition of hydrogen peroxide, addition of perchloric acid), and X-ray fluorescence (XRF) analysis

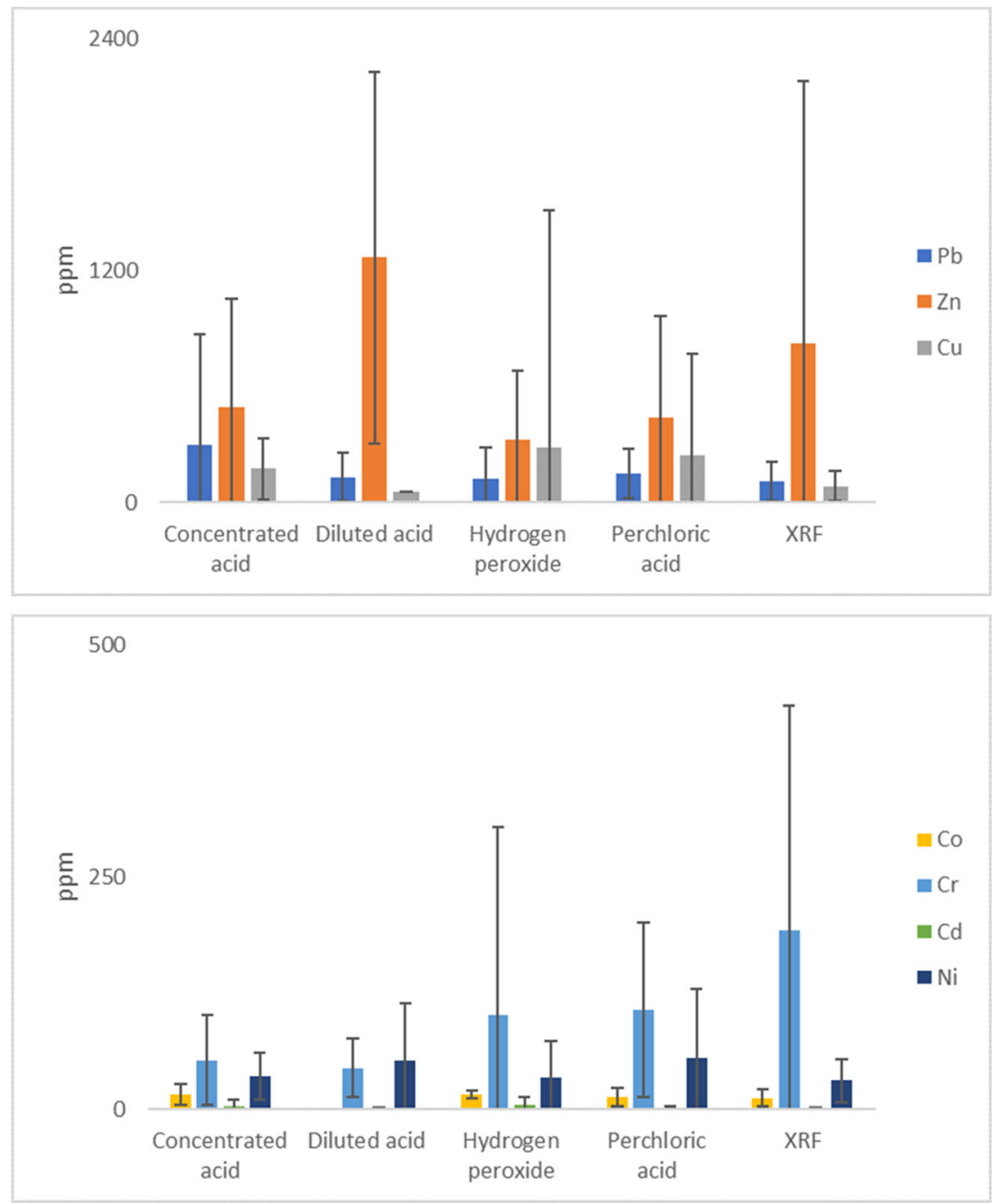


therefore, it would appear that extraction solutions that attack the sample in multiple ways are the most effective. However, the elevated XRF concentrations may suggest that extraction solutions are still not efficient when it comes to chromium dissolution. Other alloy constituents (molybdenum, manganese, etc.) not considered in this review may also contribute to the dissolution resistance of some components of urban RDS (Bellezze et al. 2018). Concentrated acids produced the highest concentrations of lead (300 ppm), with the other extraction solutions produced approximately 127 ppm (Fig. 8). The reason for this difference is unclear, as perchloric acid is a strong acid but does not appear to be as effective.

The global data on extraction methods show that most extraction procedures produce similar proportions of toxic metals, although the concentrations can vary considerably. Clear disparities are apparent when it comes to zinc and chromium concentrations. In the case of zinc, this is likely due to a small sample size and a preference for smaller grain size fractions in the diluted acid, and XRF studies. Chromium extraction appears to be enhanced when strong acids are combined with an oxidising agent (perchloric acid, hydrogen peroxide), but the concentrations are still lower than XRF values. Lead concentrations are also highest when strong acids (minus perchloric acid) are used without additional reagents. These results show that a single extraction solution is unlikely to be the most efficient extractant for every toxic metal considered. This is to be expected as the form of toxic metals in RDS can vary considerably (see emerging contaminants). Other factors such as locality and grain size fractions may have influenced the extraction data especially given the relatively low sample sizes. To achieve the comparability between global RDS studies, a routine extraction method is required. Concentrated acids are currently the most popular reagents, but there is still a significant amount of variation in this category. We suggest that concentrated nitric acid, perchloric acid and hydrofluoric acid in a ratio of 2:1:1 is used (Bian and Zhu 2009), although alternative extraction methodologies should continue to be explored.

\section{Sequential chemical extraction methods}

Another approach to chemical extractions is sequential extractions. Sequential extractions categorise different RDS geochemical fractions by the concentrations of toxic metals dissolved by specific reagents. The RDS samples are reacted with an extractant, followed by sampling and cleaning of the sample, before it is added to the next reagent. Table 4 describes two commonly used sequential extraction procedures.

Whilst the modified Community Bureau of Reference (BCR) protocol describes the extractions in a numerical fashion, it shares some similarities with the categorically defined
Tessier extraction protocol (Table 4). In summary, the first step is comparable to the "bound to carbonates" extraction, the second step is comparable to the "bound to Fe-Mn oxides" step and the third step is comparable to the "bound to organic matter" extraction. Whilst the fourth step and residual extraction use different strong acids, the overall aim of both is to dissolve silicate minerals (Tessier et al. 1979); small amounts of undissolved material may remain after these steps. Both sequential extractions were designed for use on soils and sediments. Whilst RDS contains natural substrates, most of the contaminant loading has an anthropogenic origin (Taylor and Owens 2009) which puts doubts on the relevance of these sequential extractions to RDS contamination. Nonetheless, several studies in this review have used them. Figure 9 shows the distribution of toxic metals in sequential extraction RDS studies according to the Tessier extraction protocol (Tessier et al. 1979). Some of the studies used the modified BCR protocol and were reclassified to the closest matching extractant (Rauret et al. 1999). Several studies reported percentages, whilst others reported concentrations. All the data presented here were converted to percentages so that comparisons could be made between datasets.

The data show that most of the cobalt and chromium in the RDS is associated with the residual phase (Fig. 9). As bioavailability increases from residual to exchangeable, copper and nickel are expected to be more bioavailable than cobalt and chromium as they are associated with the organic phase (Fig. 9). Lead, zinc and cadmium are evenly distributed across the carbonate, Fe and Mn oxide, and organic phases (Fig. 9), and are therefore the most bioavailable toxic metals in the RDS studied. The results highlight that lead and cadmium, two of the most toxic metals in this study, are also the most bioavailable. Previous extraction results (Fig. 9) had also shown that copper and chromium showed greater extraction efficiency when treated with a combination of strong acids and an oxidising agent. This correlates with them largely being associated with the residual fraction of the RDS and might suggest their origin is metal alloys (Bellezze et al. 2018). Cobalt and nickel are also key alloy constituents, and whilst cobalt and nickel showed no preference in the single extraction scheme (Fig. 9), they showed a preference for less bioavailable forms in the sequential extraction procedure. In the context of understanding the bioavailability of various toxic metals and the potential origin of them, sequential extractions can provide us with useful information. However, the categories used to describe the various fractions appear to have little relevance to RDS. For example, RDS contaminants are not associated with carbonates, and the organics found in RDS have different structures from those derived from the natural environment (Najmeddin and Keshavarzi 2019). In some studies, the Fe and Mn oxide phase and organic matter phase are referred to as the reducible phase and oxidizable phase, respectively, but this does not negate the fact that the same 
Table 4 Comparison of two commonly used extraction procedures (the modified BCR extraction protocol (Rauret et al. 1999) and the Tessier extraction protocol (Tessier et al. 1979))

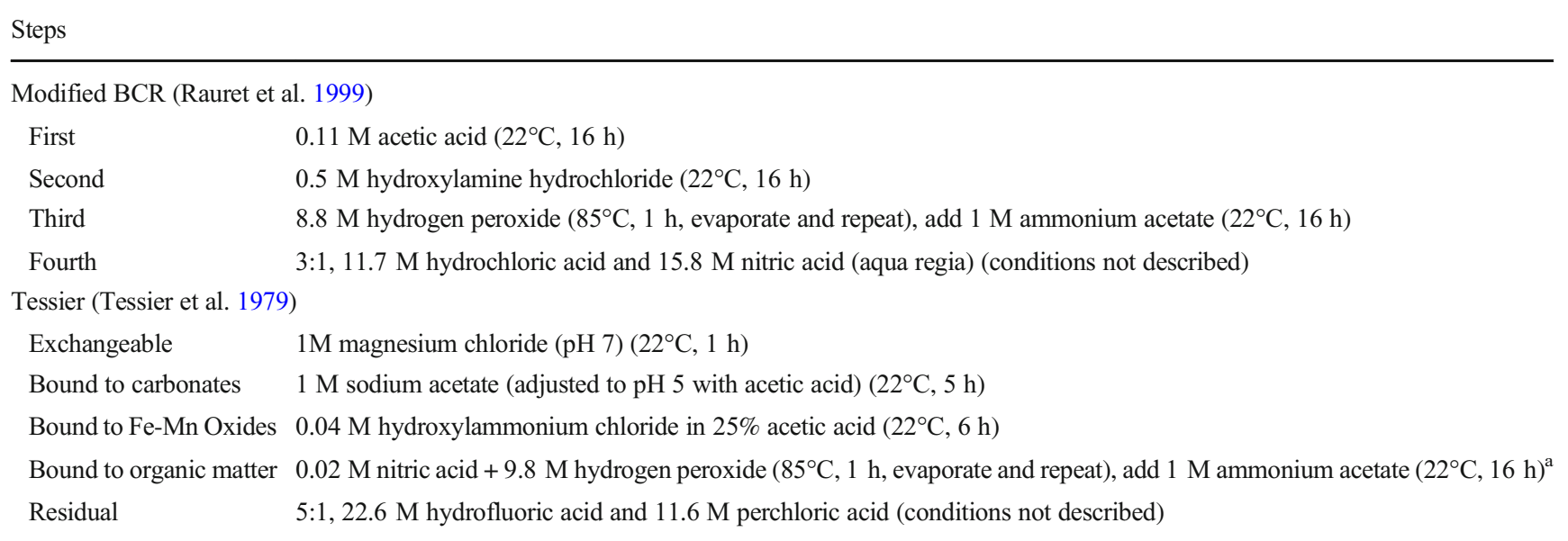

${ }^{\mathrm{a}}$ The author does not describe the experimental conditions, but a similar setup to the modified BCR extraction protocol would suffice

reagents are being used. Further research is required to understand the various compounds that toxic metals in RDS are associated with. A RDS-specific sequential extraction procedure should be devised, taking these compounds into account.

\section{Microscopy and spectroscopy methods}

As previously described, the finest grain size fraction is typically associated with the highest contaminant concentrations in RDS. Issues with sampling finer grains can make it difficult to reliably quantify contaminant concentrations and to establish the geochemical characteristics of RDS. Furthermore, whilst chemical extraction techniques can be useful for establishing bioavailable contaminant loadings in RDS, they are not particularly suitable for establishing geochemical and mineralogical characteristics of anthropogenic sediments, and accurate characterisation is essential to determine contaminant sources, fate and potential toxicity.

State-of-the-art imaging techniques such as scanning electron microscopy (SEM) and transmission electron microscopy (TEM) allow us to visualise and physically characterise very small grains and, with the addition of secondary tools (such as energy-dispersive X-ray spectroscopy (EDX)), enable the quantification and mapping of elements at the grain scale. Anthropogenic RDS particles identified using microscopy techniques include 10 - to $150-\mu \mathrm{m}$ iron-rich, toxic metalincrusted spherical particles and iron/chromium-rich angular aggregates (Bourliva et al. 2016; Byrne et al. 2017a). Spherical iron particles are often associated with high-
Fig. 9 Distribution of toxic metals in RDS in sequential extraction studies according to the Tessier extraction protocol (Tessier et al. 1979)

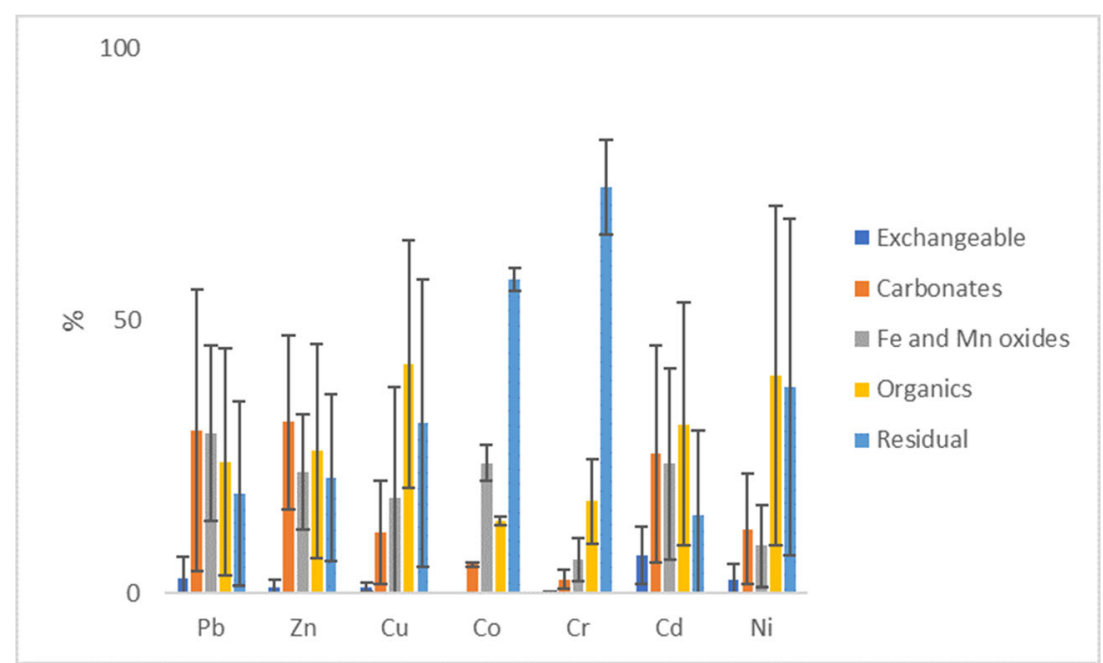


temperature combustion processes (Spiteri et al. 2005), whilst angular aggregates are associated with exhaust emissions and bodywork/engine wear (Bucko et al. 2010). Elongated particles attributed to tyre wear have also been observed (Gunawardana et al. 2012).

In recent years, molecular-scale spectroscopy techniques have increased our understanding of contaminant fate and potential toxicity. X-ray absorption spectroscopy (XAS) techniques such as X-ray absorption near-edge structure (XANES) and extended X-ray absorption fine structure (EXAFS) have allowed direct analysis of contaminant bonding structure and oxidation state. These techniques can establish contaminant toxicity and long-term behaviour with much greater accuracy than sequential chemical extraction techniques and allow environmental managers to better gauge impacts on urban ecosystems and human health. Recent XAS studies of RDS in Manchester, UK, focussed on the speciation of lead, zinc and chromium in RDS and their potential toxicity and long-term fate. Byrne et al. (2017b) established relatively high concentrations of chromium in RDS. However, XANES analysis indicated chromium in RDS grains existed mainly as $\mathrm{Cr}$ (III), indicating limited bioavailability and toxicity under the predominant environmental conditions. Only small amounts of carcinogenic $\mathrm{Cr}(\mathrm{VI})$ were detected. In similar studies, Barrett et al. (2010, 2011) used XAS techniques to establish the speciation and potential toxicity of $\mathrm{Pb}$ and $\mathrm{Zn}$ in RDS, respectively. These studies established the main metal-bearing phases for these metals in the RDS and hence the pathways by which they could pose a threat to human health. The studies also established $\mathrm{Pb}$ and $\mathrm{Zn}$ as being present in mineral phases not represented by existing sequential extraction procedures. More recent studies have considered the speciation of $\mathrm{Cr}$ and $\mathrm{Pb}$ in RDS from Daejeon, South Korea (Lee et al. 2018), and Venice, Italy (Valotto et al. 2017).

Whilst RDS studies using microscopic techniques like SEM and TEM have become more common in recent years, studies incorporating analytical techniques such as XAS are much less common. This is probably because XAS techniques require high energy and tunable $\mathrm{X}$-ray sources, such as those produced in synchrotron facilities, and synchrotron radiation sources are not widespread or easily accessible and require dedicated and expert support to operate. Although XAS techniques remain out of reach for the majority of RDS studies, substantial improvements in understating of the fate of RDS contaminants can be garnered by exploring the physical and geochemical characteristics of RDS at the microscopic scale. Therefore, we recommend supplementing chemical extraction data, where possible, with grain-specific microscopic techniques (such as SEM and TEM) to more specifically and confidently establish contaminant concentrations, loadings and geochemical phases relevant to human health and environmental quality.

\section{Establishing background contaminant loadings}

Establishing the environmental or human health risk of RDS contaminants requires consideration of background element concentrations in order to understand the magnitude of element enrichment or deviation from background concentrations. This has been achieved using a variety of methods including comparison with environmental quality guidelines (typically referring to soil contamination), average crustal concentrations, development of contamination metrics and comparison with local samples collected away from road surfaces. For example, Trujillo-Gonzalez et al. (2016) compared their data to natural metal concentrations from a previous study relevant to the local region (Fadigas et al. 2006), but comparisons to national guidelines are also common (Shi and $\mathrm{Lu}$ 2018). National and regional background values allow for more straightforward comparison of RDS studies across countries and geographical regions. However, this methodology dismisses the considerable regional and global natural variability in background element concentrations which potentially leads to inaccurate communication and risk. Local samples, on the other hand, might be influenced by factors which may not be sufficiently isolated to preclude RDS contamination, and other pollution sources might influence the results.

A more common and scientifically robust method of considering background element concentrations is calculation of so-called "geo-indices", where element concentrations of regional bedrock or pristine soils are compared with measured RDS element concentrations to establish a contamination index. One commonly used index is the geo-accumulation index $\left(I_{\text {geo }}\right)$ which relates the measured element concentration to a locally derived background concentration. Seven $I_{\text {geo }}$ classes range from no pollution $\left(I_{\text {geo }} \leq 0\right)$ to extremely polluted $\left(I_{\mathrm{geo}}>5\right)$, and a number of RDS studies have utilised this index (Lu et al. 2009; Al-Khashman 2013; Chen et al. 2013). As $I_{\text {geo }}$ and other similar metrics are based on simple ratios of a single element, they are vulnerable to distortion by particle size sorting effects and association of particular elements with particular mineral types (Bern et al. 2019). A widely used metric that can compensate for these effects is the enrichment factor (EF) which considers how much an element in a sample medium (e.g. RDS) has increased relative to average natural abundance because of human activity (Han et al. 2014). Calculation of an EF requires the selection of a background concentration and a reference element for the purpose of normalisation. However, both the selection of a background concentration and reference element data can strongly influence the result of the calculation (Bern et al. 2019) and therefore careful consideration of background geochemistry is required. 
A useful method of interrogating geochemical datasets to more accurately inform EF calculations is principal component analysis (PCA). PCA is a powerful statistical (ordination) technique for detecting patterns (similarities and dissimilarities) in geochemical datasets. It has been used frequently in geochemical (e.g. Bern et al. 2019) and water quality studies (e.g. Byrne et al. 2017a) to isolate background geochemical signatures from anthropogenic ones. The main advantage of PCA is that it integrates information for all analysed elements and compounds and can therefore yield insights (including background geochemistry) which EF and $I_{\text {geo }}$ cannot. The PCA technique has been widely applied to establish background geochemistry in RDS studies (e.g. Liu et al. 2014; Yang et al. 2019; Chen et al. 2013) and has proved a robust method for establishing environmental risk of RDS contaminants.

Understanding of the importance of using local or regional background element concentrations to establish RDS contamination levels and environmental risk has increased in recent years. RDS studies in the literature typically adopt some metric that incorporates a regional, rather than national or global, estimate of background element concentration. However, geochemical datasets must be thoroughly investigated (using PCA or other techniques) to ensure that the choices of background element and/or reference element are actually representative of the background geochemistry for the locality under study.

\section{Sample collection}

Another important aspect of RDS studies is sample collection. RDS is loosely bound as can be inferred from their transportation during storm events (Taylor and Owens 2009), and the effectiveness of road sweepers in dust cleaning (German and Svensson 2002). This means that RDS samples can be collected using basic tools such as a dustpan and brush. Other methods are used to either increase the ease with which samples can be collected (road sweeper) or improve the collection of finer particulates (vacuum). Figure 10 shows the sampling preferences of RDS surveys in this review from the year 2000 and onwards. Earlier studies were not considered due to large contaminant loadings associated with legacy data.

The use of brushing techniques, including dustpan and brushes, paint brushes and brooms, is the most used option. These methods minimise the contamination of the RDS with metals (although microplastics, for example, might be an issue) but are ineffective at sampling the finest particles (Bris et al. 1999). Dry vacuum techniques are the next most popular technique and are more effective at sampling the finest fractions (Bris et al. 1999). However, material entrained in the road surface may still be missed and any wearing of the vacuum equipment has the potential to contaminate the sample.
Wet vacuum sampling is uncommon, but likely yields the most representative sample (Gunawardana et al. 2012), with the previous caveat of the equipment contaminating the sample. Road sweepers are effective at sampling large areas (Lanzerstorfer 2018), but considerable contamination of the samples is expected. Steel scoops are rarely used and will also have the same sampling issues that are associated with brushing techniques. Outside of these techniques that directly sample the road surface, some studies will also use a range of samplers designed to collect airborne road dust particulates (Amato et al. 2014). However, this review is focused primarily on road dusts that have been deposited on the road surface (RDS). The mean concentrations of toxic metals from RDS collected using various methods (post-2000) are shown in Fig. 11.

Steel scoop values are not reported in Fig. 11 as only lead data were available, and the mean was significantly higher (3770 ppm) than the mean values for other collection methods. The steel scoop lead concentrations are considered outliers when compared to global lead RDS concentrations from the year 2000 and onwards (Fig. 11). The concentrations of toxic metals in RDS collected using brushing techniques and dry vacuum were comparable (Fig. 11). Road sweeping produced the lowest concentrations of most toxic metals, apart from zinc, chromium and nickel where wet vacuum produced the lowest values (Fig. 11). Wet vacuuming produced the highest concentrations of lead, but the concentrations of the other toxic metals were low compared to other methods (Fig. 11). The results of the collection review are unclear. Part of the problem is that the sample size for road sweeping and wet vacuum is low (Fig. 10), and even in the case of brushing and dry vacuum where the sample size is higher (Fig. 10), the standard deviation is still high (Fig. 11). Most of this variation will be due to differences in user operation of the equipment, differences between equipment (broom, paintbrush, etc.) and differences in locality. However, trends with grain size fractions (Fig. 6), extraction reagents (Fig. 8) and sequential extractions (Fig. 9) are observable in the global dataset. This suggests that the sampling method is not as important as other factors when it comes to understanding the toxic metal loading of RDS. Despite this, further work should be undertaken to evaluate if vacuum methods (especially wet vacuum) can produce a more representative concentration of toxic metals associated with RDS. In terms of suggesting a suitable sampling method, another consideration is the availability of sampling equipment. Brushing techniques are universally available, whilst road sweeping requires municipal assistance. Vacuum techniques can scale in cost from simple household appliances, to specialised vacuums designed for scientific purposes, and therefore are not universally accessible. In terms of standardisation, it consequently seems sensible to suggest dustpan and brush sampling, with further sampling using vacuum techniques if accessible. This will produce a more standardised 
Fig. 10 Breakdown of road dust sampling procedures used by studies in this review from the year 2000 and onwards

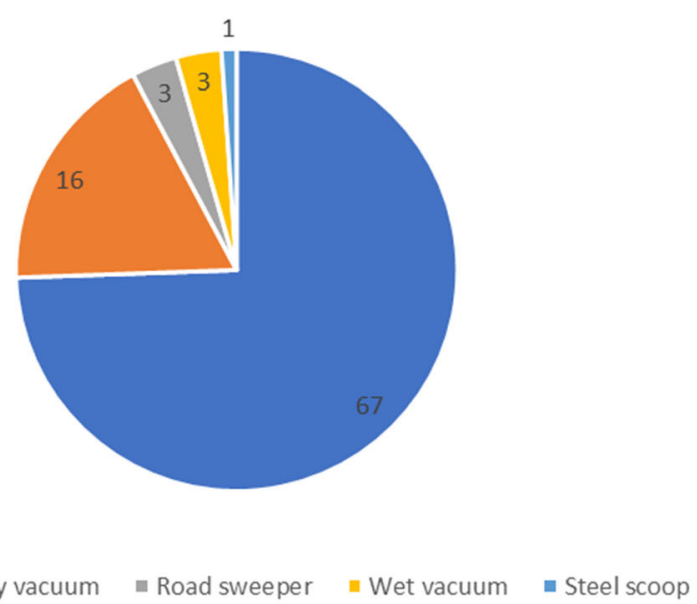

way of producing RDS surveys, whilst allowing for further development of collection techniques.

\section{Emerging contaminant loadings}

\subsection{PGEs}

The platinum group elements (PGEs) are a series of elements known for their catalytic properties. The PGEs include ruthenium, rhodium, palladium, osmium, iridium and platinum. In the case of the automotive industry, PGEs are incorporated into catalytic converters where they catalyse the transformation of nitrogen oxides $\left(\mathrm{NO}_{x}\right)$, unburnt hydrocarbons and carbon monoxide into nitrogen, carbon dioxide and water (Santos and Costa 2009). Two-way (oxidizing) catalysts use a combination of platinum and palladium to treat unburnt hydrocarbons and carbon monoxide (Samuels et al. 1982), whilst three-way catalysts also include rhodium to treat nitrogen oxides (Ribbens 2013). Automotive catalysts also contain ruthenium, osmium and iridium in the form of impurities (Rauch and Peucker-Ehrenbrink 2015). PGE emissions from automotive exhausts occur as a result of the degradation of the catalyst surface due to chemical reactions and mechanical wear (Moldovan et al. 2003). The emission of PGEs from catalytic converters decreases with car mileage, with one study suggesting PGE emissions are approximately $1490 \mathrm{~g} \mathrm{year}^{-1}$ for Madrid, Spain, and $2460 \mathrm{~g} \mathrm{year}^{-1}$ for Sweden (Moldovan et al. 2002). A number of hazards are associated with PGEs in RDS including their mobilisation and solubilisation by environmental compounds (Dahlheimer et al. 2007), the formation of halogenated PGE complexes in lung fluid (Colombo et al. 2008) and the health risks associated with airborne particulate matter (Bennett et al. 2019).

Palladium and platinum accounted for the highest concentrations of PGEs in global RDS, with mean values of $158 \mathrm{ppb}$
Fig. 11 Mean concentrations of toxic metals in RDS (post-2000) collected using various methods

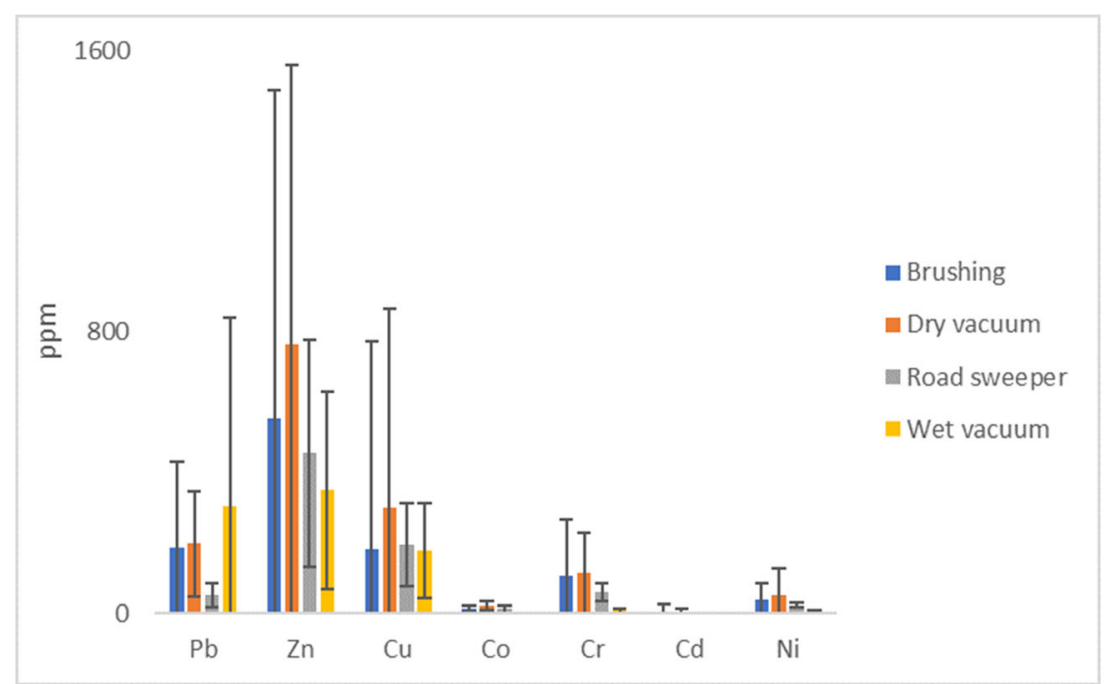


and $128 \mathrm{ppb}$, respectively (Fig. 12). Rhodium had a mean value of $27.7 \mathrm{ppb}$, whilst iridium (1.56 ppb), ruthenium (4.81 ppb) and osmium (0.0701 ppb) mean values were much lower (Fig. 12). The PGE concentrations in RDS were reflective of catalytic converter usage. Platinum was the dominant PGE in two-way and three-way catalysts (Ravindra et al. 2004), but as stricter emission standards were set, the automotive industry shifted towards palladium-richer catalysts (Zereini et al. 2007). Platinum and rhodium ratios in Germany during 1997 were approximately 5:1 (Zereini et al. 1997) which was consistent with the ratio found in this review. This suggests that rhodium usage in catalytic converters has not changed significantly. The other PGE concentrations are consistent with them being impurities. However, information on osmium concentrations was scarce, with only two studies in this review reporting osmium values (Qi et al. 2011; Zhao et al. 2014). No temporal trends were observable in the PGE data. This was likely due to a combination of issues, including differences between gasoline and diesel catalytic converters (Moldovan et al. 2002) and differences between catalytic converter specifications in international markets (due to differences in emission standards) (EU 2007; USEPA 2014), along with the range of vehicle ages on the road (Moldovan et al. 2002).

The data in this study confirmed that the PGE content of urban RDS was directly related to catalytic converter usage.
More research is required when it comes to understanding the hazard associated with the PGE content of urban RDS, and RDS studies can contribute to this by providing information on their concentrations, as well as their association with grain size fractions. Aside from the health concerns, it is also important to consider the impact of catalytic converters on the global supply of PGEs. PGEs are some of the scarcest elements on Earth and are crucial to a variety of sectors including medicine and electronics (Zientek et al. 2017). These sectors are reliant on the recycling of PGEs in order to maintain supply (Zientek et al. 2017). Catalytic converters are one of the largest markets for PGEs (Ravindra et al. 2004). It is therefore concerning that PGEs are being removed from reuse via deposition on road surfaces. The concentration of PGEs in ores primarily mined for their presence is between 5 and $15 \mathrm{ppm}$ (Zientek et al. 2017). The average total concentration of PGEs in RDS in this study was $321 \mathrm{ppb}$, making it unlikely that RDS can be an economic source of PGEs. Research into the reduction and removal of PGE contents from catalytic converters (Fesik et al. 2013) is thus vital in terms of health consequences and PGE availability.

\subsection{PAHs}

Several other RDS contaminants have started receiving greater attention over the last decade. This is partly down to the
Fig. 12 Concentrations of platinum group metals (PGEs) in global RDS presented in a box and whisker plot, along with the accompanying data

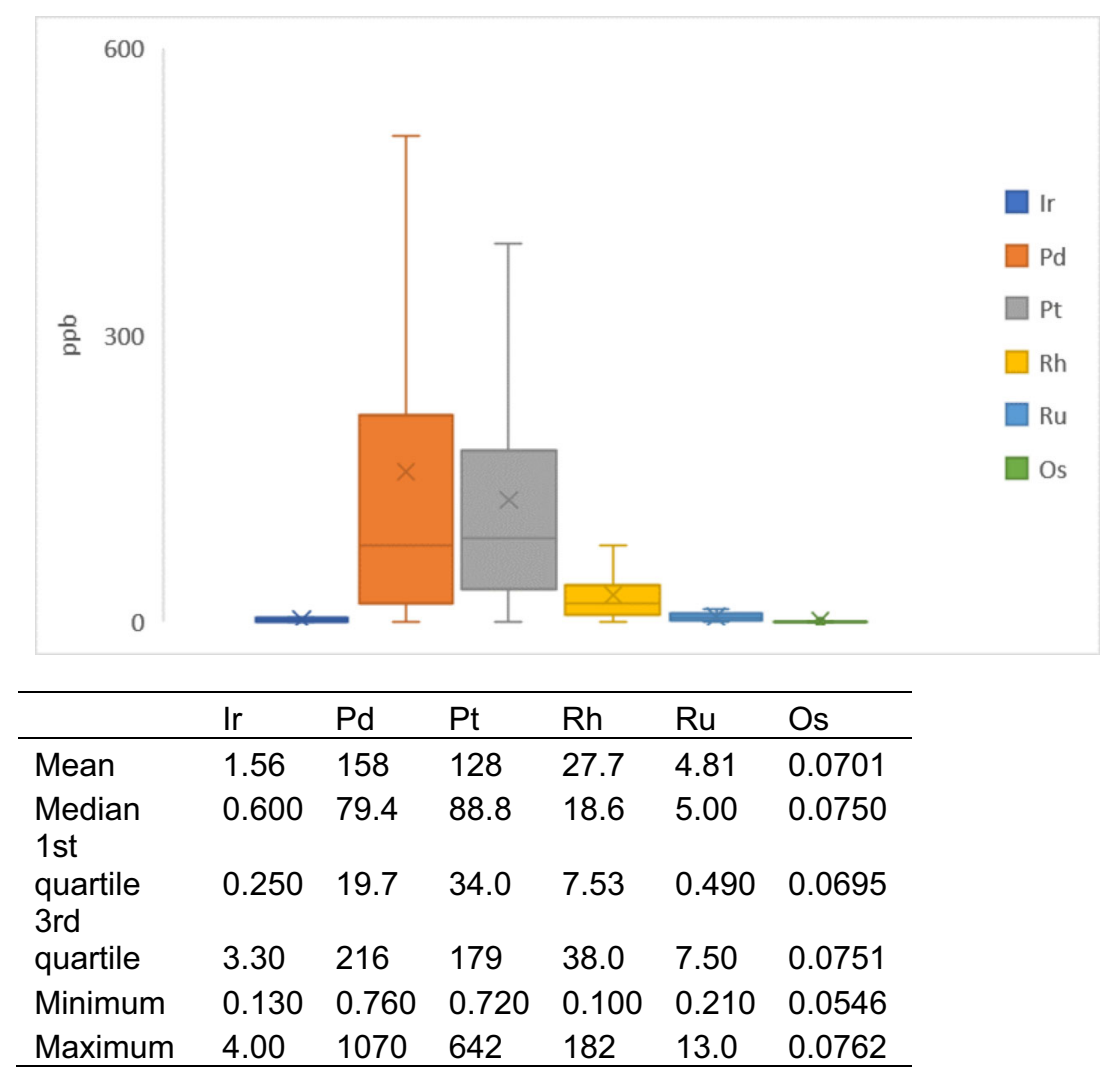


development of new analytical techniques that can provide us with information on the harmful contaminants in RDS, and the reclassification of hazardous substances. One key area for emerging contaminants is organic molecules. A variety of anthropogenically derived organics is an environmental concern including pesticides, herbicides, hydrocarbons, PCBs, PAHs and dioxins (Taylor and Owens 2009). The most relevant of these to RDS and automotive emissions are polycyclic aromatic hydrocarbons. PAHs are produced during the combustion of fossil fuels and biofuels (Najmeddin and Keshavarzi 2019). The main concerns associated with PAHs are their carcinogenic properties (Suman et al. 2016) and their potential to be absorbed through the respiratory system (and other exposure routes) due to their association with $\mathrm{PM}_{10}$ particulates (Di Vaio et al. 2016). The term PAH is used to define hydrocarbons that contain more than one aromatic ring and includes a broad range of organic molecules including naphthalene and anthracene. In total, 16 PAHs are considered priority pollutants by the USEPA (Najmeddin and Keshavarzi 2019). In order to assess such a wide variety of molecules, the PAH content of RDS is typically analysed using highperformance liquid chromatography (HPLC) (Hussain et al. 2015) or gas chromatography mass spectrometry (GCMS) (Najmeddin and Keshavarzi 2019). The risk associated with PAHs is often determined by calculating the incremental lifetime cancer risk (ILCR) for the ingestion, dermal contact and inhalation of benzo[a]pyrene (BaP) (Peng et al. 2011). A value

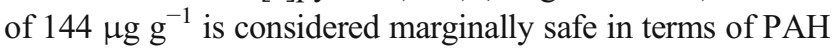
exposure (Peng et al. 2011).

The investigation of other emerging contaminants is still in development. New techniques allow us to identify RDS hazards from a different perspective. Anthropogenic activity has been shown to increase the magnetisation of sediments (Yang et al. 2007). The magnetisation of contaminants can be used to discern them from naturally occurring material and provide information on the contaminants present (Bourliva et al. 2016). Magnetite is the dominant magnetic mineral found in RDS and is generated from exhaust emissions, tyre wear, brake linings and the road surface (Bucko et al. 2010). Anthropogenic magnetite has been identified in human brain tissue and has been linked to Alzheimer's disease (Maher et al. 2016). The toxic metals previously described in this study may also be concentrated in the magnetic fractions of RDS (Bourliva et al. 2016). Microplastics are produced by the degradation of a range of plastic products and are typically defined as plastic particles with a size of less than $5 \mathrm{~mm}$ (Frias and Nash 2019). Vehicles produce microplastics via the wearing of tyres, brake use and the abrasion of road markings (Kole et al. 2017). Tyre wear contributes to between 3 and $7 \%$ of $\mathrm{PM}_{2.5}$ and between 5 and $10 \%$ of ocean plastic (Kole et al. 2017). Microplastics accumulate in the food chain, leading to a range of health issues in a variety of organisms and in humans (Chae and An 2017). The collection of microplastics in the environment poses similar challenges to that encountered during the collection of other fine-grained particulate matter (Alves et al. 2018). Furthermore, the detection and quantification of microplastics in environmental samples is complicated, with research required to improve cost and efficiency (Zarfl 2019). A shift towards electric vehicles may lead to an increase in tyre wear (Timmers and Achten 2016) and therefore microplastic deposition. However, road surface design can play a role in reducing tyre wear and may also capture microplastics, allowing for their safe disposal after cleaning (Kole et al. 2017).

\section{Proposed workflow for future studies}

As global populations rise the number, the proportion of people living in urbanised areas increases (UN 2019a). Urbanised areas are associated with a variety of pollution sources. One of these sources is RDS. RDS contains a range of naturally derived sediments and anthropogenic particulates (Taylor and Owens 2009). Historically, RDS has been contaminated with toxic metals as a result of industrial activities (Brunekreef et al. 1981), and lead from leaded gasoline combustion (deMiguel et al. 1997). As these contaminant loadings have reduced in the urban environment, the focus has shifted towards toxic metals released from non-exhaust automotive sources (Adamiec et al. 2016). A requirement to curb greenhouse gas emissions is leading to shifts in the market towards hybrid and electric vehicles (Timmers and Achten 2016). This advancement in automotive technologies is expected to impact the toxic metal loading of RDS. Other emerging contaminants including PGEs associated with catalytic converters (Wiseman et al. 2018), fine-grained particulate matter (Alves et al. 2018), organic molecules (Najmeddin and Keshavarzi 2019) and microplastics (Kole et al. 2017) are starting to receive more attention, and understanding them is vital in improving health and the environment. The key aims of this review were to evaluate current urban RDS contaminant loadings, in order to understand their impact on future urban centres. Whilst assessing global RDS contaminants, it was clear that many variables influence their composition. A number of these variables relate to the locality such as climatic conditions (Chon et al. 1998), emission standards (EU 2007) and road maintenance and cleaning (Stojiljkovic et al. 2019). However, several of these variables are due to differences between sampling and analysis regimes. In order to improve the comparability between RDS studies, a workflow diagram is proposed here (Fig. 13).

The first thing to consider when conducting a RDS survey is the sample location. Sample location may partially be dictated by institution location and the safe accessibility of appropriate urban road surfaces. Sampling regimes should be representative of the urban environment, i.e. high traffic density, paved 


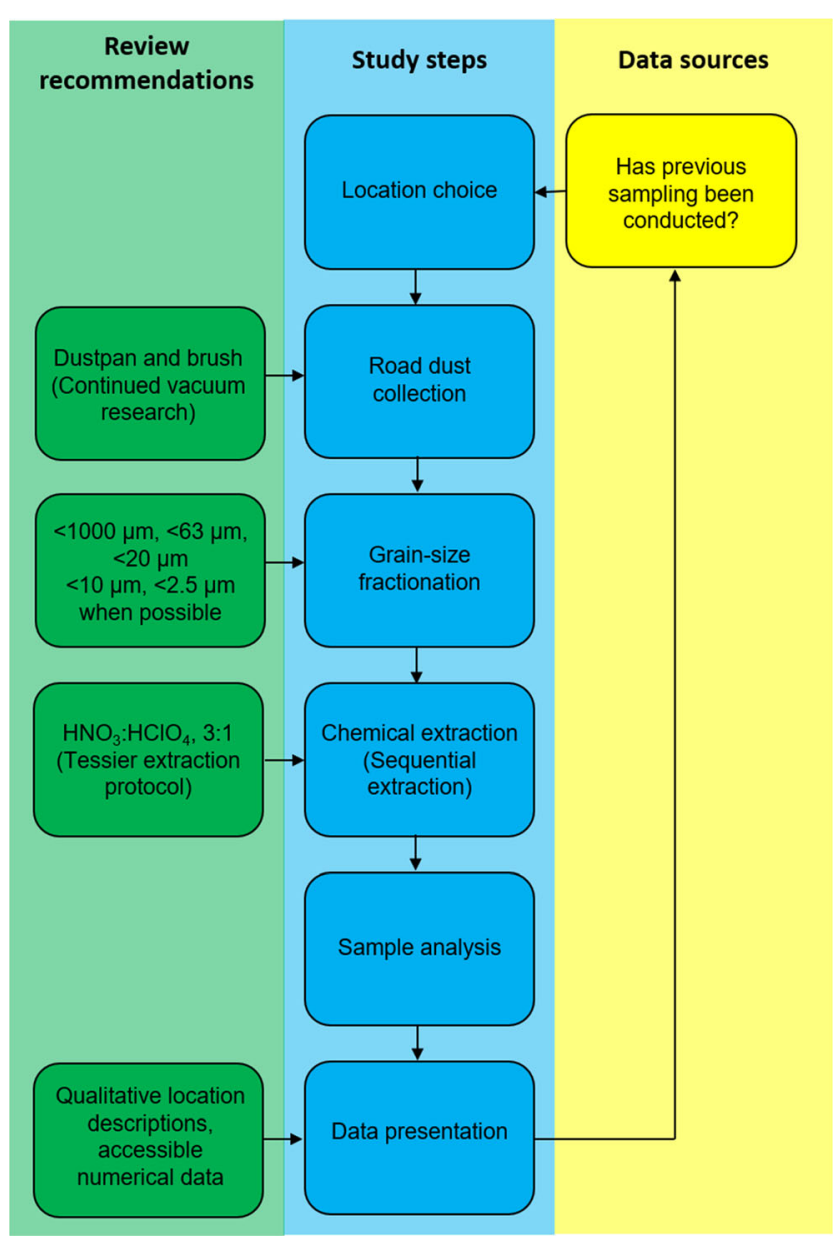

Fig. 13 Workflow diagram depicting the key steps in carrying out a RDS survey. Blue boxes indicate the tasks that need to be completed, green boxes show the suggestions on conducting these tasks highlighted in the review, and yellow boxes indicate suggestions for other data sources to consider when conducting the RDS survey

surfaces and majority of land adjacent to roads dedicated to buildings (Robertson et al. 2003). It is also important to avoid point sources (heavy industry, etc.) which could lead to overestimation of RDS loadings (Brunekreef et al. 1981). When possible, previous RDS sampling of the location should be taken into consideration so that temporal RDS datasets can be compiled. Current RDS surveys can promote the development of temporal data by providing information on the sites in the survey. Seasonal events including firework displays (Yang et al. 2019) and forest fires (Ramirez et al. 2018) may also influence the results, as well as rain (Chon et al. 1998) and snow (Stojiljkovic et al. 2019). Therefore, RDS should be surveyed after a period of dry weather at a time when atmospheric pollutant loadings are normal for that region.

Once a sampling regime has been developed, the next consideration is the sample collection equipment. Several collection techniques were identified in this review including brushing techniques (Shi and $\mathrm{Lu} 2018$ ), vacuum techniques (Adamiec et al. 2016) and road sweepers (Viklander 1998).
Analysis of collection techniques highlighted considerable margins of error for all collection techniques (Fig. 11). In terms of bulk RDS concentrations, it was not possible to determine the most appropriate technique. However, of the two most commonly used techniques (brushing and dry vacuum), dry vacuum is more effective at collecting fine particles (Bris et al. 1999). This is an important consideration as the highest contaminant loadings in RDS are often associated with the finest fractions (Fig. 6). Another factor is the availability of collection equipment. Brushing techniques are universally available, whilst vacuum equipment requires investment and, if not designed for scientific purposes, could contaminate the samples. Individual technique, when it comes to using any collection method, will also impart a large degree of variability. Overall, sweeping is likely to be the most suitable technique for standardisation purposes, but continued research into vacuum techniques is recommended.

Having collected the RDS samples, the next step is to separate samples into grain size fractions. Stepwise sieving was the most popular choice in this review (Fig. 5) and provides a discrete set of grain size ranges. Different grain size fractions can provide us information on the hazard and transportability of the RDS. For example, sampling of RDS less than $1000 \mu \mathrm{m}$ provides information on the bulk load of toxic metals (Fig. 6), less than $63 \mu \mathrm{m}$ (silt) identifies transportable contaminants (Taylor and Owens 2009) whilst less than $10 \mu \mathrm{m}$ and $2.5 \mu \mathrm{m}$ grain size fractions highlight respirable contaminants (Lanzerstorfer 2018). Dry sieving is the most accessible fractionation technique, but the finest sieve is $20 \mu \mathrm{m}$ (Lanzerstorfer 2018). Using the dry sieving technique, we recommend analysing the $63-1000 \mu \mathrm{m}, 20-63 \mu \mathrm{m}$ and less than $20 \mu \mathrm{m}$ grain size fractions. Where equipment permits, the $2.5 \mu \mathrm{m}$ and $10 \mu \mathrm{m}$ fractions should also be investigated as they are the greatest hazard to human health (Bennett et al. 2019).

When RDS has been separated into appropriate grain size fractions, the next step is to prepare it for analysis. XRF can be used to determine a wide range of elements in solid-state samples (Hetem and Andrade 2016). However, more commonly, the sample is dissolved in order to determine the concentrations of chosen elements in the aqueous phase (Fig. 7). Aqueous samples are typically analysed using atomic absorption spectroscopy (AAS) (Zafra et al. 2011) or inductively coupled plasma (ICP) atomic emission spectroscopy (AES) (Deocampo et al. 2012) and mass spectroscopy (MS) (Han et al. 2014). A range of chemicals have been used to dissolve RDS samples, but they can be broadly classified into concentrated strong acids, oxidising agents and diluted acids (including weak acids) (Figs. 7 and 8). Studies that used perchloric acid were categorised separately as it is a strong acid and an oxidising agent. This review showed that the addition of hydrogen peroxide and perchloric acid to reagent mixtures produced higher concentrations of chromium typically associated with automotive alloys (Bellezze et al. 2018), whilst strong 
acids produced higher concentrations of lead (Fig. 8). In order to standardise extraction solutions across RDS surveys, we suggest using concentrated nitric acid with perchloric acid in a ratio of 3:1. Although the use of hydrofluoric acid can lead to more efficient extraction of metals (e.g. Barrett et al. 2010), stringent procedures govern its storage, use and disposal, and so the use of hydrofluoric acid is not recommended here. Two commonly used extraction protocols are the modified BCR protocol and the Tessier extraction protocol (Tessier et al. 1979). This review assessed the results based on the qualitative descriptions used in the Tessier extraction protocol (exchangeable, bound to carbonates, bound to Mn-Fe oxides, bound to organics, residual). Caution should be taken when using these classifications as these protocols were developed for natural soils and sediments (Tessier et al. 1979) and therefore were not developed with anthropogenic particles in mind. Nonetheless, these categories give us an understanding of the bioavailability of RDS contaminants, with exchangeable being the most bioavailable and residual the least bioavailable. The sequential extraction results showed that cobalt, copper, chromium and nickel were the least bioavailable toxic metals in RDS, whilst cadmium, lead and zinc are associated with more bioavailable fractions (Fig. 9).

After collecting the data for the RDS survey, the presentation of the data should be done in a manner that allows for it to be incorporated into future RDS studies providing a foundation on which further work can be added. RDS data are presented in studies in a variety of formats including tabled data, scatter graphs, bar charts and maps detailing spatial distribution (Chon et al. 1998). RDS data may also be interpreted in the form of principal component analyses (Shi and $\mathrm{Lu} 2018$ ) or analysed to produce enrichment factors (Cai and Li 2019) or health risk assessments (Duan et al. 2017). Whilst these interpretations are important in understanding local implications of urban RDS contamination, the inconsistency of their use between studies makes it difficult to extrapolate the results to a global scale. Therefore, it is essential that numerical values for urban RDS concentrations are reported, preferably in a format that can be easily extracted from the study. Another important consideration when it comes to applying localised data to global studies is qualitative descriptions of the sampling sites. Some sampling sites may be in rural locations or intended as background samples (Akhter and Madany 1993). In cases where it is highlighted, these datum points can be excluded from global urban RDS datasets ensuring only samples representative of the urban environment are included. Other descriptions such as place names may help to determine where the sampling took place which is useful for repeat studies (Du et al. 2013). However, their significance may not be understood by an audience away from the immediate locality.

Overall, this review and the workflow diagram can highlight the important factors that need consideration when it comes to producing toxic metal data from urban RDS that are comparable with global studies. The workflow diagram is designed in a way that promotes current data being produced in a manner that can be easily accessed by future work, creating a foundation on which global RDS studies can be conducted in a standardised manner, whilst simultaneously providing space for further innovation. The focus of this workflow diagram is toxic metals. However, key phases of it will be applicable to PGEs, organics and other emerging contaminants. Standardised RDS surveys can remove some of the variation from RDS datasets which will allow us to identify trends in an increasingly urbanised environment and generate more focused discussions on the elimination of hazardous materials from road surfaces.

\section{Recommendations for future monitoring and research}

A comprehensive analysis of the global literature on urban RDS contamination was conducted in order to identify recommendations for future analyses and research directions. Key recommendations are:

1. Bulk and sequential chemical extractions are a useful method to determine bioavailable and residual geochemical fractions of contaminants in RDS. However, evidence from microscopic and spectroscopic investigations suggests contaminant mineralogy does not align with the geochemical phases that common chemical extraction methods focus on. Verification of contaminant geochemistry through microscopic analysis techniques is therefore recommended to enable more robust conclusions to be drawn on contaminant mobility, fate and environmental risk.

2. Consideration of background element concentrations is fundamental to understand environmental risk. This is commonly considered in the literature through contaminant enrichment metrics. However, caution is advised when selecting background values and reference elements and thorough analysis of the geochemical data (through PCA for example) is recommended to derive elements and concentrations that accurately represent background geochemical signatures.

3. As well as spatial monitoring and studies, temporal datasets are also important for understanding seasonal and longer-term trends and changes in pollutant loading in urban systems.

4. From a geographical perspective, there is a lack of data and studies from Africa, even though urban populations have increased and will continue to increase significantly. 
Open Access This article is licensed under a Creative Commons Attribution 4.0 International License, which permits use, sharing, adaptation, distribution and reproduction in any medium or format, as long as you give appropriate credit to the original author(s) and the source, provide a link to the Creative Commons licence, and indicate if changes were made. The images or other third party material in this article are included in the article's Creative Commons licence, unless indicated otherwise in a credit line to the material. If material is not included in the article's Creative Commons licence and your intended use is not permitted by statutory regulation or exceeds the permitted use, you will need to obtain permission directly from the copyright holder. To view a copy of this licence, visit http://creativecommons.org/licenses/by/4.0/.

\section{References}

Adamiec E, Jarosz-Krzeminska E, Wieszala R (2016) Heavy metals from non-exhaust vehicle emissions in urban and motorway road dusts. Environ Monit Assess 188:1-11

Akhter MS, Madany IM (1993) Heavy-metals in street and house dust in Bahrain. Water Air Soil Pollut 66:111-119

Alikin EA, Bochkarev SY, Denisov SP, Danchenko NM, Rychkov VN, Volkov AS, Karpov AS (2013) Thermally stable composite system $\mathrm{Al} 2 \mathrm{O} 3-\mathrm{Ce} 0.75 \mathrm{Zr} 0.25 \mathrm{O} 2$ for automotive three-way catalysts. Catal Ind 5:133-142

Al-Khashman OA (2013) Assessment of heavy metals contamination in deposited street dusts in different urbanized areas in the city of Ma'an, Jordan. Environ Earth Sci 70(6):2603-2612

Alves CA, Evtyugina M, Vicente AMP, Vicente ED, Nunes TV, Silva PMA, Duarte MAC, Pio CA, Amato F, Querol X (2018) Chemical profiling of PM10 from urban road dust. Sci Total Environ 634:4151

Amato F, Alastuey A, de la Rosa J, Gonzalez Castanedo Y, Sanchez de la Campa AM, Pandolfi M, Lozano A, Contreras Gonzalez J, Querol X (2014) Trends of road dust emissions contributions on ambient air particulate levels at rural, urban and industrial sites in southern Spain. Atmos Chem Phys 14:3533-3544

Barrett JES, Taylor KG, Hudson-Edwards KA, Charnock JM (2010) Solid-phase speciation of $\mathrm{Pb}$ in urban road dust sediment: a XANES and EXAFS study. Environ Sci Technol 44:2940-2946

Barrett JES, Taylor KG, Hudson-Edwards KA, Charnock JM (2011) Solid-phase speciation of $\mathrm{Zn}$ in road dust sediment. Mineral Mag 75:2611-2629

Beckwith PR, Ellis JB, Revitt DM, Oldfield F (1986) Heavy-metal and magnetic relationships for urban source sediments. Phys Earth Planet Inter 42:67-75

Bellezze T, Giuliani G, Vicere A, Roventi G (2018) Study of stainless steels corrosion in a strong acid mixture. Part 2: anodic selective dissolution, weight loss and electrochemical impedance spectroscopy tests. Corros Sci 130:12-21

Benhaddya ML, Boukhelkhal A, Halis Y, Hadjel M (2016) Human health risks associated with metals from urban soil and road dust in an oilfield area of southeastern Algeria. Arch Environ Contam Toxicol 70:556-571

Bennett JE, Tamura-Wicks H, Parks RM, Burnett RT, Pope CA, Bechle MJ, Marshall JD, Danaei G, Ezzati M (2019) Particulate matter air pollution and national and county life expectancy loss in the USA: a spatiotemporal analysis. PLoS Med 16:e1002856

Bern CR, Walton-Day K, Naftz DL (2019) Improved enrichment factor calculations through principal component analysis: examples from soils near breccia pipe uranium mines, Arizona, USA. Environ Pollut 248:90-100

Bian B, Zhu W (2009) Particle size distribution and pollutants in roaddeposited sediments in different areas of Zhenjiang, China. Environ Geochem Health 31:511-520
Bourliva A, Papadopoulou L, Aidona A (2016) Study of road dust magnetic phases as the main carrier of potentially harmful trace elements. Sci Total Environ 553:380-391

Bris FJ, Garnaud S, Apperry N, Gonzalez A, Mouchel JM, Chebbo G, Thevenot DR (1999) A street deposit sampling method for metal and hydrocarbon contamination assessment. Sci Total Environ 235: 211-220

Brunekreef B, Veenstra SJ, Biersteker K, Boleij JSM (1981) The Arnhem lead study: 1. Lead uptake by 1 -year-old to 3 -year-old children living in the vicinity of a secondary lead smelter in Arnhem, the Netherlands. Environ Res 25:441-448

Bucko MS, Magiera T, Pesonen LJ, Janus B (2010) Magnetic, geochemical, and microstructural characteristics of road dust on roadsides with different traffic volumes-case study from Finland. Water Air Soil Pollut 209:295-306

Byrne P, Runkel RL, Walton-Day K (2017a) Synoptic sampling and principal components analysis to identify sources of water and metals to an acid mine drainage stream. Environ Sci Pollut Res 24: $17220-17240$

Byrne P, Taylor KG, Hudson-Edwards KA, Barrett JES (2017b) Speciation and potential long-term behaviour of chromium in urban sediment particulates. J Soils Sediments 17:2666-2676

Cai K, Li C (2019) Street dust heavy metal pollution source apportionment and sustainable management in a typical city-Shijiazhuang, China. Int J Environ Res Public Health 16(14):2625

Chae Y, An YJ (2017) Effects of micro- and nanoplastics on aquatic ecosystems: current research trends and perspectives. Mar Pollut Bull 124:624-632

Charlesworth SM, Lees JA (1999) The distribution of heavy metals in deposited urban dusts and sediments, Coventry, England. Environ Geochem Health 21:97-115

Chen H, Lu X, Chang Y, Xue W (2013) Heavy metal contamination in dust from kindergartens and elementary schools in Xi'an, China. Environ Earth Sci 71(6):2701-2709

Chon HT, Ahn JS, Jung MC (1998) Seasonal variations and chemical forms of heavy metals in soils and dusts from the satellite cities of Seoul, Korea. Environ Geochem Health 20:77-86

Colombo C, Monhemius AJ, Plant JA (2008) Platinum, palladium and rhodium release from vehicle exhaust catalysts and road dust exposed to simulated lung fluids. Ecotoxicol Environ Saf 71:722-730

Dahlheimer SR, Neal CR, Fein JB (2007) Potential mobilization of platinum-group elements by siderophores in surface environments. Environ Sci Technol 41:870-875

Day JP, Hart M, Robinson MS (1975) Lead in urban street dust. Nature 253:343-345

deMiguel E, Llamas JF, Chacon E, Berg T, Larssen S, Royset O, Vadset M (1997) Origin and patterns of distribution of trace elements in street dust: unleaded petrol and urban lead. Atmos Environ 31: 2733-2740

Deocampo DM, Reed PJ, Kalenuik AP (2012) Road dust lead (Pb) in two neighborhoods of urban Atlanta, (GA, USA). Int J Environ Res Public Health 9:2020-2030

Di Vaio P, Cocozziello B, Corvino A, Fiorino F, Frecentese F, Magli E, Onorati G, Saccone I, Santagada V, Settimo G, Severino B, Perissutti E (2016) Level, potential sources of polycyclic aromatic hydrocarbons (PAHs) in particulate matter (PM10) in Naples. Atmos Environ 129:186-196

Du Y, Gao B, Zhou H, Ju X, Hao H, Yin S (2013) Health risk assessment of heavy metals in road dusts in urban parks of Beijing, China. 2013 Int Sym Environ Sci Technol (2013 ISEST) 18:299-309

Duan ZB, Wang J, Zhang Y, Xuan B (2017) Assessment of heavy metals contamination in road dust from different functional areas in Guiyang Southwest China. Int J Environ Sci Educ 12:427-439

Duggan MJ, Williams S (1977) Lead-in-dust in city streets. Sci Total Environ 7:91-97 
EU (2007) Type approval of motor vehicles with respect to emissions from light passenger and commercial vehicles (euro 5 and euro 6) and on access to vehicle repair and maintenance information. EU, Brussels

Fadigas FDS, Amaral Sobrinho ND, Mazur N, Anjos LD, Freixo AA (2006) Proposição de valores de referência para a concentração natural de metais pesados em solos brasileiros. R Bras Eng Agríc Ambient 10:699-705

Fesik EV, Zarazhevskii VI, Grebnev VV, Mal'chikov GD (2013) Rhenium- and ruthenium-containing catalysts for neutralization of automobile exhaust. Kinet Catal 54:626-631

Frias J, Nash R (2019) Microplastics: finding a consensus on the definition. Mar Pollut Bull 138:145-147

Fujiwara F, Jimenez Rebagliati R, Dawidowski L, Gomez D, Polla G, Pereyra V, Smichowski P (2011) Spatial and chemical patterns of size fractionated road dust collected in a megacitiy. Atmos Environ 45:1497-1505

Gallacher JEJ, Elwood PC, Phillips KM, Davies BE, Jones DT (1984) Relation between pica and blood lead in areas of differing leadexposure. Arch Dis Child 59:40-44

German J, Svensson G (2002) Metal content and particle size distribution of street sediments and street sweeping waste. Water Sci Technol 46:191-198

Gilbert SG, Weiss B (2006) A rationale for lowering the blood lead action level from 10 to $2 \mathrm{mu} \mathrm{g} / \mathrm{dL}$. Neurotoxicology 27:693-701

Goonetilleke A, Wijesiri B, Bandala ER (2017) Water and soil pollution implications of road traffic. In: Environmental Impacts of Road Vehicles: Past, Present and Future, vol 44, pp 86-106

Goyer RA (1993) Lead toxicity - current concerns. Environ Health Perspect 100:177-187

Gulia S, Shiva Nagendra SM, Khare M, Khanna I (2015) Urban air quality management-a review. Atmos Pollut Res 6:286-304

Gunawardana C, Goonetilleke A, Egodawatta P, Dawes L, Kokot S (2012) Source characterisation of road dust based on chemical and mineralogical composition. Chemosphere 87:163-170

Hamad SH, Shafer MM, Kadhim AKH, Al-Omran SM, Schauer JJ (2015) Seasonal trends in the composition and ROS activity of fine particulate matter in Baghdad, Iraq. Atmos Environ 100:102-110

Han Y, Cao J, Posmentier ES, Fung K, Tian H, An Z (2008) Particulateassociated potentially harmful elements in urban road dusts in Xi'an, China. Appl Geochem 23:835-845

Han NMM, Latif MT, Othman M, Dominick D, Mohamad N, Juahir H, Tahir NM (2014) Composition of selected heavy metals in road dust from Kuala Lumpur city centre. Environ Earth Sci 72:849-859

Hao H, Geng Y, Sarkis J (2016) Carbon footprint of global passenger cars: scenarios through 2050. Energy 101:121-131

Harrison RM, Yin JX (2000) Particulate matter in the atmosphere: which particle properties are important for its effects on health? Sci Total Environ 249:85-101

Hetem IG, Andrade MD (2016) Characterization of fine particulate matter emitted from the resuspension of road and pavement dust in the metropolitan area of Sao Paulo, Brazil. Atmos 7:31

Ho YB (1979) Lead contamination in street dust in Hong-Kong. Bull Environ Contam Toxicol 21:639-642

Hussain K, Rahman M, Prakash A, Hoque RR (2015) Street dust bound PAHs, carbon and heavy metals in Guwahati city - seasonality, toxicity and sources. Sustain Cities Soc 19:17-25

Hwang H-M, Fiala MJ, Park D, Wade TL (2016) Review of pollutants in urban road dust and stormwater runoff: part 1 . Heavy metals released from vehicles. Int J Urban Sci 20:334-360

Inskip MJ, Hutton M (1987) Lead-based paint in dwellings - the potential for contamination of the home-environment during renovation. Environ Geochem Health 9:86-92

Kole PJ, Lohr AJ, Van Belleghem F, Ragas AMJ (2017) Wear and tear of tyres: a stealthy source of microplastics in the environment. Int $\mathrm{J}$ Environ Res Public Health 14:1265
Lanzerstorfer C (2018) Heavy metals in the finest size fractions of roaddeposited sediments. Environ Pollut 239:522-531

Lee PK, Chang HJ, Yu S, Chae KH, Bae JH, Kang MJ, Chae G (2018) Characterization of $\mathrm{Cr}(\mathrm{VI})$ - containing solid phase particles in dry dust deposition in Daejon, South Korea. Environ Pollut 243:16371647

Liang W, Yang M (2019) Urbanization, economic growth and environmental pollution: evidence from China. Sustain Comput Infor 21:1-9

Liu E, Yan T, Birch G, Zhu Y (2014) Pollution and health risk of potentially toxic metals in urban road dust in Nanjing, a mega-city of China. Sci Total Environ 476-477:522-531

Lu X, Wang L, Lei K, Huang J, Zhai Y (2009) Contamination assessment of copper, lead, zinc, manganese and nickel in street dust of Baoji, NW China. J Hazard Mater 161(2-3):1058-1062

Mafuyai GM, Kamoh NM, Kangpe NS, Ayuba SM, Eneji IS (2015) Heavy metals contamination in roadside dust along major traffic roads in Jos metropolitan area Nigeria. J Environ Earth Sci 5:280 293

Maher BA, Ahmed IAM, Karloukovski V, MacLaren DA, Foulds PG, Allsop D, Mann DMA, Torres-Jardon R, Calderon-Garciduenas L (2016) Magnetite pollution nanoparticles in the human brain. Proc Natl Acad Sci U S A 113:10797-10801

Maina EG, Gachanja AN, Gatari MJ, Price H (2018) Demonstrating PM2.5 and road-side dust pollution by heavy metals along Thika superhighway in Kenya, sub-Saharan Africa. Environ Monit Assess 190:251

McAlister JJ, Smith BJ, Neto JB, Simpson JK (2005) Geochemical distribution and bioavailability of heavy metals and oxalate in street sediments from Rio de Janeiro, Brazil: a preliminary investigation. Environ Geochem Health 27:429-441

Milani M, Pucillo FP, Ballerini M, Camatini M, Gualtieri M, Martino S (2004) First evidence of type debris characterization at the nanoscale by focused ion beam. Mater Charact 52:283-288

Miranda ML, Anthopolos R, Hastings D (2011) A geospatial analysis of the effects of aviation gasoline on childhood blood lead levels. Environ Health Perspect 119:1513-1516

Moldovan M, Palacios MA, Gomez MM, Morrison G, Rauch S, McLeod C, Ma R, Caroli S, Alimonti A, Petrucci F, Bocca B, Schramel P, Zischka M, Pettersson C, Wass U, Luna M, Saenz JC, Santamaria J (2002) Environmental risk of particulate and soluble platinum group elements released from gasoline and diesel engine catalytic converters. Sci Total Environ 296:199-208

Moldovan M, Rauch S, Morrison GM, Gomez M, Palacios MA (2003) Impact of ageing on the distribution of platinum group elements and catalyst poisoning elements in automobile catalysts. Surf Interface Anal 35:354-359

Najmeddin A, Keshavarzi B (2019) Health risk assessment and source apportionment of polycyclic aromatic hydrocarbons associated with PM10 and road deposited dust in Ahvaz metropolis of Iran. Environ Geochem Health 41:1267-1290

Nicholson FA, Smith SR, Alloway BJ, Carlton-Smith C, Chambers BJ (2003) An inventory of heavy metals inputs to agricultural soils in England and Wales. Sci Total Environ 311:205-219

Owens PN, Caley KA, Campbell S, Koiter AJ, Droppo IG, Taylor KG (2011) Total and size-fractionated mass of road-deposited sediment in the city of Prince George, British Columbia, Canada: implications for air and water quality in an urban environment. J Soils Sediments 11:1040-1051

Peng C, Chen WP, Liao XL, Wang ME, Ouyang ZY, Jiao WT, Bai Y (2011) Polycyclic aromatic hydrocarbons in urban soils of Beijing: status, sources, distribution and potential risk. Environ Pollut 159: 802-808

Qi L, Zhou M-F, Zhao Z, Hu J, Huang Y (2011) The characteristics of automobile catalyst-derived platinum group elements in road dusts and roadside soils: a case study in the Pearl River Delta region, South China. Environ Earth Sci 64:1683-1692 
Ramirez O, de la Campa AMS, Amato F, Catacoli RA, Rojas NY, de la Rosa J (2018) Chemical composition and source apportionment of PM10 at an urban background site in a high-altitude Latin American megacity (Bogota, Colombia). Environ Pollut 233:142-155

Rauch S, Peucker-Ehrenbrink B (2015) Sources of platinum group elements in the environment. In: Zerini F, Wiseman C (eds) Platinum metals in the environment. Springer, Berlin, pp 3-17

Rauret G, Lopez-Sanchez JF, Sahuquillo A, Rubio R, Davidson C, Ure A, Quevauviller P (1999) Improvement of the BCR three step sequential extraction procedure prior to the certification of new sediment and soil reference materials. J Environ Monit 1:57-61

Ravindra K, Bencs L, Van Grieken R (2004) Platinum group elements in the environment and their health risk. Sci Total Environ 318:1-43

Ribbens WB (2013) The basics of electronic engine control. In: Ribbens WB, Mansour NP, Luecke G, Battle CW, Jones EC, Mansir LE (eds) Understanding automotive electronics, 3rd edn. ButterworthHeinemann, Oxford, pp 177-231

Robertson DJ, Taylor KG, Hoon SR (2003) Geochemical and mineral magnetic characterisation of urban sediment particulates, Manchester, UK. Appl Geochem 18:269-282

Samuels G, Rose A, David G, Hooker J, Auer P (1982) Energy conservation in transportation. In: Auer P (ed) Advances in energy systems and technology. Academic, London, pp 187-297

Santos H, Costa M (2009) Modelling transport phenomena and chemical reactions in automotive three-way catalytic converters. Chem Eng J 148:173-183

Shi D, Lu X (2018) Accumulation degree and source apportionment of trace metals in smaller than $63 \mathrm{mu}$ m road dust from the areas with different land uses: a case study of Xi'an, China. Sci Total Environ 636:1211-1218

Simons A (2016) Road transport: new life cycle inventories for fossilfuelled passenger cars and non-exhaust emissions in ecoinvent $\mathrm{v} 3$. Int J Life Cycle Assess 21:1299-1313

Sperling D, Dill J (1988) Unleaded gasoline in the United States: a successful model of system innovation. Transp Res Rec 45-52

Spiteri C, Kalinski V, Rosler W, Hoffmann V, Appel E, Team M (2005) Magnetic screening of a pollution hotspot in the Lausitz area, eastern Germany: correlation analysis between magnetic proxies and heavy metal contamination in soils. Environ Geol 49:1-9

Stojiljkovic A, Kauhaniemi M, Kukkonen J, Kupiainen K, Karppinen A, Denby BR, Kousa A, Niemi JV, Ketzel M (2019) The impact of measures to reduce ambient air PM10 concentrations originating from road dust, evaluated for a street canyon in Helsinki. Atmos Chem Phys 19:11199-11212

Stone M, Marsalek J (1996) Trace metal composition and speciation in street sediment: Sault Ste Marie, Canada. Water Air Soil Pollut 87: 149-169

Suman S, Sinha A, Tarafdar A (2016) Polycyclic aromatic hydrocarbons (PAHs) concentration levels, pattern, source identification and soil toxicity assessment in urban traffic soil of Dhanbad, India. Sci Total Environ 545:353-360

Sutherland RA (2003) Lead in grain size fractions of road-deposited sediment. Environ Pollut 121:229-237

Talbot DEJ, Talbot JDR (2018) Corrosion science and technology. CRC, Boca Raton

Tanner PA, Ma H-L, Yu PKN (2008) Fingerprinting metals in urban street dust of Beijing, Shanghai, and Hong Kong. Environ Sci Technol 42:7111-7117

Taylor KG, Owens PN (2009) Sediments in urban river basins: a review of sediment-contaminant dynamics in an environmental system conditioned by human activities. J Soils Sediments 9:281-303

Tessier A, Campbell PGC, Bisson M (1979) Sequential extraction procedure for the speciation of particulate trace-metals. Anal Chem 51: 844-851
Thorpe A, Harrison RM (2008) Sources and properties on nonexhaust particulate matter from road traffic: a review. Sci Total Environ 400: 270-282

Timmers V, Achten PAJ (2016) Non-exhaust PM emissions from electric vehicles. Atmos Environ 134:10-17

Trujillo-Gonzalez JM, Torres-Mora MA, Keesstra S, Brevik EC, Jimenez-Ballesta R (2016) Heavy metal accumulation related to population density in road dust samples taken from urban sites under different land uses. Sci Total Environ 553:636-642

UN (2019a) World urbanization prospects the 2018 revision. UN, New York

UN (2019b) World population prospects 2019. UN, New York

USEPA (1973) Toxic materials analysis of street surface contaminants. USEPA, Washington DC

USEPA (2014) Control of air pollution from motor vehicles: tier 3 motor vehicle emission and fuel standards. USEPA, Washington DC

USEPA (2019) Hazard standards for lead in paint, dust and soil (TSCA section 403). USEPA, Washington DC

Valotto G, Cattaruzza E, Bardelli F (2017) Multi-edge X-ray absorption spectroscopy study of road dust samples from a traffic area of Venice using stoichiometric and environmental references. Spectrochim Acta A 173:971-978

Viklander M (1998) Particle size distribution and metal content in street sediments. J Environ Eng Asce 124:761-766

Wager G, Whale J, Braunl T (2018) Performance evaluation of regenerative braking systems. Proc Inst Mech Eng D 232:1414-1427

Wei B, Yang L (2010) A review of heavy metal contaminations in urban soils, urban road dusts and agricultural soils from China. Microchem J 94:99-107

Wentworth CK (1922) A scale of grade and class terms for clastic sediments. J Geol 30:377-392

Wijaya AR, Ouchi AK, Tanaka K, Shinjo R, Ohde S (2012) Metal contents and $\mathrm{Pb}$ isotopes in road-side dust and sediment of Japan. J Geochem Explor 118:68-76

Wiseman CLS, Niu J, Levesque C, Chenier M, Rasmussen PE (2018) An assessment of the inhalation bioaccessibility of platinum group elements in road dust using a simulated lung fluid. Environ Pollut 241: 1009-1017

Xie XZ, Semanjski I, Gautama S, Tsiligianni E, Deligiannis N, Rajan RT, Pasveer F, Philips W (2017) A review of urban air pollution monitoring and exposure assessment methods. ISPRS Int J Geo Inf 6:389

Xing YF, Xu YH, Shi MH, Lian YX (2016) The impact of PM2.5 on the human respiratory system. J Thorac Dis 8:E69-E74

Xu HM, Cao JJ, Ho KF, Ding H, Han YM, Wang GH, Chow JC, Watson JG, Khol SD, Qiang J, Li WT (2012) Lead concentrations in fine particulate matter after the phasing out of leaded gasoline in Xi'an, China. Atmos Environ 46:217-224

Yang T, Liu QS, Chan LS, Cao GD (2007) Magnetic investigation of heavy metals contamination in urban topsoils around the East Lake, Wuhan, China. Geophys J Int 171:603-612

Yang SC, Li P, Liu JL, Bi XY, Ning YQ, Wang S, Wang PC (2019) Profiles, source identification and health risks of potentially toxic metals in pyrotechnic-related road dust during Chinese New Year. Ecotoxicol Environ Saf 184. https://doi.org/10.1016/j.ecoenv.2019. 109604

Yeung ZLL, Kwok RCW, Yu KN (2003) Determination of multielement profiles of street dust using energy dispersive X-ray fluorescence (EDXRF). Appl Radiat Isot 58:339-346

Zafra CA, Temprano J, Tejero I (2011) Distribution of the concentration of heavy metals associated with the sediment particles accumulated on road surfaces. Environ Technol 32:997-1008

Zanders JM (2005) Road sediment: characterization and implications for the performance of vegetated strips for treating road run-off. Sci Total Environ 339:41-47 
Zarfl C (2019) Promising techniques and open challenges for microplastic identification and quantification in environmental matrices. Anal Bioanal Chem 411:3743-3756

Zereini F, Skerstupp B, Alt F, Helmers E, Urban H (1997) Geochemical behaviour of platinum-group elements (PGE) in particulate emissions by automobile exhaust catalysts: experimental results and environmental investigations. Sci Total Environ 206:137-146

Zereini F, Wiseman C, Puttmann W (2007) Changes in palladium, platinum, and rhodium concentrations, and their spatial distribution in soils along a major highway in Germany from 1994 to 2004. Environ Sci Technol 41:451-456

Zhang J, Chen CM, Zhang XY, Liu ST (2016a) Study on the environmental risk assessment of lead-acid batteries. In: Tenth International Conference on Waste Management and Technology, vol 31, pp 873-879
Zhang JS, Everson MP, Wallington TJ, Field FR, Roth R, Kirchain RE (2016b) Assessing economic modulation of future critical materials use: the case of automotive-related platinum group metals. Environ Sci Technol 50:7687-7695

Zhao PP, Li J, Zhong LF, Sun SL, Xu JF (2014) A method for determination of PGE-Re concentrations and Os isotopic compositions in environmental materials. Anal Methods 6:5537-5545

Zientek ML, Loferski PJ, Parks HL, Schulte RF, Seal II RR (2017) Platinum group elements. USGS professional paper 1802-N. USGS, Reston

Publisher's note Springer Nature remains neutral with regard to jurisdictional claims in published maps and institutional affiliations. 